\title{
Dynamic response of plates on elastic foundation under eccentric impact load
}

\author{
Mohammed Y. Fattah ${ }^{1, *}$ Mohammed J. Hamood ${ }^{1}$, and Sura A. Abbas ${ }^{1}$ \\ ${ }^{1}$ Building and Construction Engineering Department, University of Technology, Baghdad, \\ Iraq
}

\begin{abstract}
In this study, nonlinear three-dimensional finite element analysis has been used to conduct a numerical investigation of the effect of applied impact load on the foundation based on sandy soil using the finite element method by ANSYS (Version 11) computer program. The 8-node brick elements are used to model the concrete of foundation and the soil under the foundation which are denoted by Solid 65 for concrete and Solid 45 for the soil while the interface is modeled by using three-dimensional surface-to-surface (Target 170 and Contact 174) contact elements connected with concrete and soil. As a case study, a square concrete foundation with dimensions of $3 \times 3 \times 0.3 \mathrm{~m}$ placed on the foundation soil 15 $\mathrm{m}$ deep and $9 \mathrm{~m}$ away from the edge of plate is subjected to impact load. A parametric study is carried out to investigate the effect of several parameters including: foundation thickness, load eccentricity and amplitude of impact load. It was concluded that the load eccentricity increases the displacement and decreases the stress at the foundation center. This is attributed to non-uniformly distributed stresses on the loaded area, where the loads are concentrated locally within the loaded area. The presence of damping leads to a considerable decrease in the foundation displacements and stresses. The increase in the damping ratio reduces the vertical displacement of the foundation at the same time at all damping ratios.
\end{abstract}

\section{Introduction}

Plates on elastic foundation are often used in civil engineering problems, such as building infrastructures, tanks or silo foundations, aerospace engineering etc. [1].

Plates are commonly used structural elements and are subjected to wide variety of static and dynamic loads. Broadly, the dynamic loads can be classified into three major categories:

- Steady state harmonic loads.

- Random loads as in the case of seismic excitation on tall buildings.

- Impulsive or shock loads as in the case of hammer foundations, missile impact, blast loads on structures, or an aircraft crashing against a civil engineering

\footnotetext{
${ }^{*}$ Corresponding author: myf 1968@yahoo.com
} 
structure. The term "impact" covers a wide range of topics that are of great interest to do the research work.

\section{Previous studies on plates resting on soil}

The literature generally refers to three distinguished methods, these are:

1) Analytical methods:

The earliest formulation of the foundation model was due to Winkler (1867) [2]. This model represents a continuous elastic foundation by a set of closely spaced independent linear springs. Since the foundation is characterized only by springs, the Winkler type model is also called one-parameter model. The vertical displacement at the foundation surface, $w$ is related to the intensity of applied load (q) or to the foundation reaction (p) by the modulus of the foundation and is defined as the reaction of the foundation per unit surface area per unit deflection [3]. In order to eliminate the deficiency of Winkler model, improved theories have been introduced on refinement of Winkler's model, by visualising various types of interconnections such as shear layers and beams along the Winkler springs [4-7). These theories have been attempted to find an applicable and simple model of representation of foundation medium [8].

Levinton (1949) introduced a simplified method to analyze beams on elastic foundations, in which the contact pressure is represented by a number of redundant reactions [9]. Another foundation model was proposed by Pasternak in 1954 [6], which acquires shear interaction between springs by connecting the ends of the springs to a layer consisting of incompressible vertical elements which deform only by transverse shearing. This class of mathematical models has another constant parameter which characterizes the interaction implied between springs and hence is called twoparameter models. Two-parameter foundation models are more accurate than the one parameter (e.g. Winkler) foundation model.

Wang and How (2001) analyzed the rectangular thick raft resting on a homogeneous elastic half space [10]. They used the Mindlin plate theory to model the raft in order to allow for the effect of transverse shear deformation in the raft as it bends under transverse loading. By approximating the displacement function using complete two-dimensional polynomials of sufficient degree, the Ritz method was shown to be an accurate technique in solving this class of the raft-soil interaction problems. They compared the settlement and the bending moment of the raft for various loading conditions.

2) Experimental methods:

Al-Azawi (1984) tested experimentally simply supported reinforced concrete slabs subjected to both impact loading and static loading [11]. The impact load was produced by a freely falling steel mass which impacted a $(50 \mathrm{~mm}$ diameter x $500 \mathrm{~mm}$ long) cylindrical steel bar placed in contact with the slab at its center. The adopted variables were the falling mass, the boundary conditions of the slabs, and the slab thickness. A theoretical analysis was carried out to determine the deflection-time history at the center of a reinforced concrete slab. The central transient deflection of the slabs was calculated and found in a good agreement with the experimental transient deflection.

Abbasi et al. (1992) analyzed reinforced concrete beams and plates under impact loading [12]. Three-dimensional nonlinear finite element analysis of the reinforced concrete has been modeled. Experiments were conducted in the laboratory involving drop hammer loading on circular concrete slabs. The load cell was fixed in position so that it could not displace off its position when the penetrating mass impinges on the specimen. The impact velocity was measured with help of a simple 
photo gate type arrangement. The results showed good agreement of the predicted values with their experiments.

Baidya (2004) presented an experimental study on the natural frequency of a foundation on a layered soil system subjected to dynamic loading [13]. It was observed that the natural frequency of the system decreases due to presence of the soft layer at the top, whereas it increases due to presence of the stiff layer at the top. It was also observed that presence of a soft layer at top is more dangerous than at depth.

Fujikake and Soeun (2009) studied the impact responses of simply supported reinforced concrete beams through an experimental study and presented an analytical model to predict the maximum midspan deflection and maximum impact load, to evaluate the damage levels of reinforced concrete $(\mathrm{RC})$ beams when subjected to impact loadings [14]. The experimental impact responses of the RC beams were simulated with a two degree-of-freedom mass- spring-damper system model, in which the loading rate effects were duly considered.

3) Numerical and finite element methods:

Emrich et al. (1982) used finite element method to investigate the behavior of reinforced concrete beams subjected to impact load. Nonlinear constitutive laws for concrete and steel were assumed [15]. Newmark implicit time scheme was used to solve nonlinear dynamic equations. A consistent mass matrix was used; neither structural nor material damping was considered. Results were verified by results from experiments and were in good agreement.

Miyamoto et al. (1991) used Dracker-Prager to model concrete when they investigate the analytical and numerical failure modes of reinforced concrete slabs subjected to impulse loads [16]. They examined the rate of dynamic load, the maximum deflection in the center, the impulse load-midspan deflection curves from zero to ultimate load, the propagation of cracks through the cross section, and the pattern at failure. The numerical failure mode was determined as well as the load rating in failure mode and the distribution of cracking while they carried out a comprehensive study in this field.

Tameroglu (1996) studied a different solution technique for free vibrations of rectangular plates with clamped boundaries resting on elastic foundations and subjected to uniform and constant compressive, unidirectional forces in the mid- plane [17]. The method was based on the use of a non-orthogonal series expansion consisting of some specially chosen trigonometric functions for the deflection surface (w) of the plate. The orthogonalization of the series and other calculations were performed using Fourier expansion of Bernoulli polynomials under some realistic approximations for the limiting values of the boundary conditions. It was concluded that by this method, one does not need to use the solution of the differential equation of the problem.

Tee (2005) studied the dynamic response of a finite circular plate resting on sand by using ABAQUS program [18]. In the analysis, a free-drop impact system was considered to generate the dynamic loading on the plate free surface. Two finite element models were built, one with a slide line underneath the target plate and another one without the slide line. The numerical results of the finite element method for the radial strain at the bottom of the target plate were compared with the experimental measurement. The numerical results showed good agreement with the experimental results.

Borgerhoff et al. (2011) presented the analyses of impact tests of reinforced concrete slabs with dominating punching behavior and confirmed that the layered shell element of the program SOFiSTiK was suitable for a reliable numerical simulation of the problem, provided that the slabs had a minimum of transverse reinforcement, which was sufficient to assure that the ultimate limit state with respect to punching is not 
exceeded [19]. The requirement was the implicitly fulfilled in the design of a structure which has to resist a specified impact load. In the case of checking reinforced concrete plates without shear reinforcement (or with significant exceedance of punching resistance), empirical perforation formulae or analyses by use of simple two-mass vibration models are applicable.

Mahmoudpour et al. (2011) presented a coupled scaled boundary finite element model to examine the dynamic response of a structure considering the soil-structure interaction [20]. The analysis was performed in time domain. The material behavior of soil and structure was assumed to be linear. They reported that when the system was subjected to sine excitation, the reduction in displacement and base shear was more significant when the loading frequency was close to natural frequencies of the structure.

Based on the literature reviewed, it is found that many literatures are reported on nonlinear behavior of soil and concrete, and considerable amount of literatures are reported on the three-dimensional nonlinear analysis of plate on elastic foundation, but very few studies adopted the dynamic response of soil-structure interaction problems. The present research aims to analyze the foundation by three-dimensional nonlinear finite element method using ANAYS 11 finite element software, in which both the structure and its supporting soil are modeled as continua. The foundation and soil are discretized by eight nodded brick elements. The soil is modeled as elasto-plastic material. The finite element procedure is used to analyze the foundation subjected to concentrated impact load.

\section{Description of the problem}

The present finite element formulations and solution procedures are applied to the transient dynamic analysis of a plate on elastic foundation with material nonlinearities. A concrete foundation with dimensions of $3 \times 3 \times 0.3 \mathrm{~m}$ is placed on the foundation soil $15 \mathrm{~m}$ deep and $9 \mathrm{~m}$ away from the edge of plate. The boundary conditions are chosen such that all the lateral boundaries and the base of the problem are restricted both horizontally and vertically. The geometry, loading conditions and all details of the problem are shown in Figure (1).

The foundation is subjected to the transient dynamic load described by the following equation:

where:

$$
\begin{gathered}
f(t)=0.5-0.5 \cos \left(2 \pi t / T_{o}\right) \\
p(t)=p_{o} f(t)
\end{gathered}
$$

t: time for each point,

$\mathrm{T}_{\mathrm{o}}$ : impact duration, and

$\mathrm{p}_{\mathrm{o}}$ : the peak amplitude of the load.

The loading function is shown in Figure 2. The duration of this dynamic load is 0.5 seconds with a time step $(\Delta t=0.01 \mathrm{sec}$.). The properties of the material for concrete and soil are summarized in Table 1 . The soil foundation is cohesionless dense sand with an angle of internal friction, $f$ equals $40^{\circ}$. The nonlinear behavior for both soil and concrete is considered. The Drucker-Prager model is used to model the soil elasto-plastic behavior, while the linear elastic model is used for modeling the behavior of concrete. The 8-node brick elements in ANSYS are used to represent the concrete of foundation and the soil under the foundation which are denoted by Solid 65 for concrete and Solid 45 for the soil, and the interface between the concrete and supporting soil is modeled by using three-dimensional surface-to-surface (Target 170 and Contact 174) contact elements connected with concrete and soil [21]. 
The load is applied at the foundation center for eccentric loading and at distances of ( $\mathrm{e} / \mathrm{B}=0.1,0.2,0.3$, where $\mathrm{B}$ is the width of the foundation) away from the center for concentric loading. No damping has been considered in this problem.

\section{Parametric study}

A parametric study is performed to investigate the influence of several important parameters on the behavior of the foundation on elastio-plastic soil subjected to impact loads. The parameters studied are foundation thickness, load eccentricity and amplitude.

The analysis is carried out by the program (ANSYS V11) [22]. The parameters used in the analysis are summarized in Table 2.

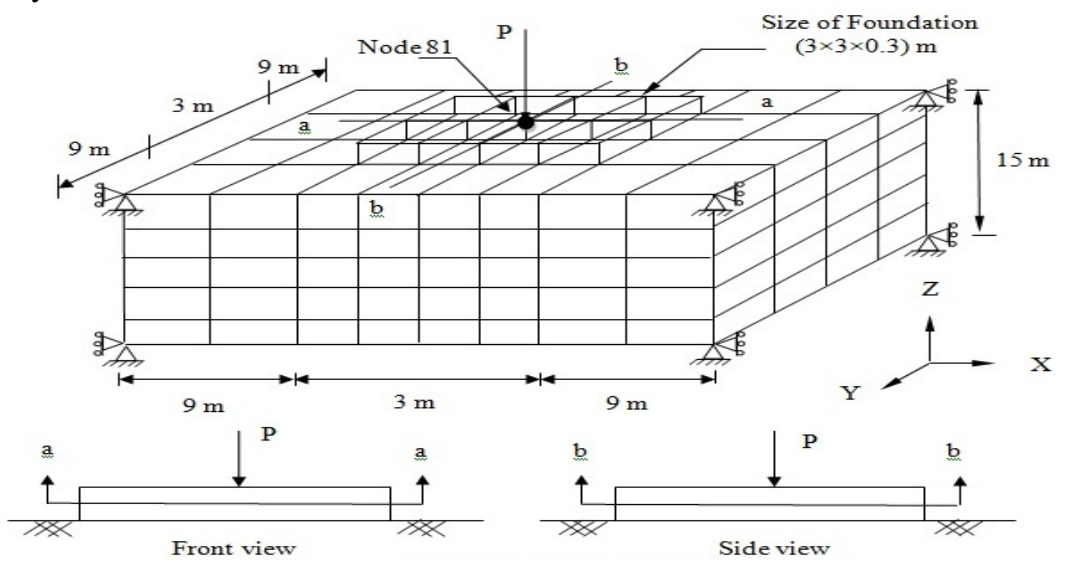

Fig. 1: Typical finite element mesh.

Table 1: Material properties for concrete and soil in the basic problem.

\begin{tabular}{|l|l|l|l|}
\hline \multirow{5}{*}{ Concrete } & Symbol & Definition & Value \\
\cline { 2 - 4 } & $\mathrm{f}_{\mathrm{c}}$ & Compressive strength $(\mathrm{MPa})$ & 25 \\
\cline { 2 - 4 } & $E_{c}$ & Young's modulus $(\mathrm{MPa})$ & 23500 \\
\cline { 2 - 4 } & $\mathrm{f}_{\mathrm{t}}$ & Tensile strength $(\mathrm{MPa})$ & 3.1 \\
\cline { 2 - 4 } Interface & $\mathrm{v}$ & Poisson's ratio & $0.15^{*}$ \\
\cline { 2 - 4 } & $\rho_{\mathrm{c}}$ & Density $\left(\mathrm{kg} / \mathrm{m}^{3}\right)$ & 2400 \\
\hline \multirow{5}{*}{ Soil } & $\mu$ & Coefficient of friction & $0.6^{*}$ \\
\hline & Es & Young's modulus $(\mathrm{MPa})$ & 50 \\
\cline { 2 - 4 } & $\mathrm{c}_{\mathrm{u}}$ & Cohesion & 0 \\
\cline { 2 - 4 } & $\phi$ & Frication angle & $40^{\circ}$ \\
\cline { 2 - 4 } & $v$ & Poisson's ratio & $0.3^{*}$ \\
\cline { 2 - 4 } & $\rho_{\mathrm{s}}$ & Density $\left(\mathrm{kg} / \mathrm{m}^{3}\right)$ & 1800 \\
\hline
\end{tabular}

Notes: Assumed value, $E_{c}=4700 \sqrt{f^{\prime} c}$ and $f_{t}=0.62 \sqrt{f^{\prime} c}$. 


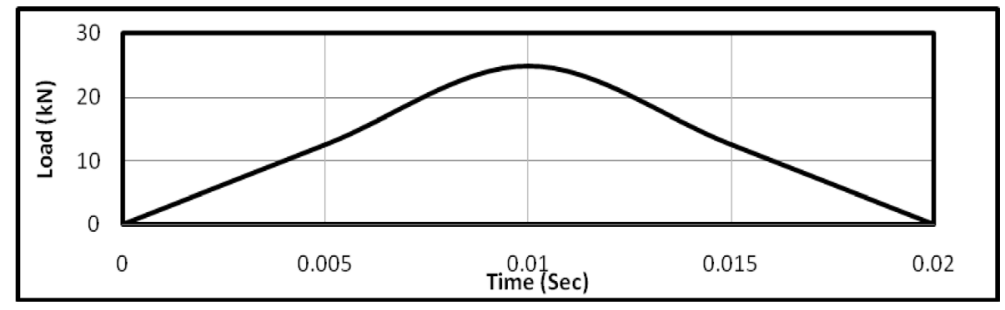

Fig. 2: The loading function.

Table 2: Parameters of the main problem.

\begin{tabular}{|l|l|l|}
\hline parameter & Range of value & Unit \\
\hline Foundation thickness & $0.3,0.5,0.75$ & $\mathrm{~m}$ \\
\hline Foundation length & $3,4,5,6$ & $\mathrm{~m}$ \\
\hline Load amplitude, $\mathrm{p}_{\mathrm{o}}$ & $25,75,100$ & $\mathrm{kN}$ \\
\hline
\end{tabular}

\section{Results and discussion}

The eccentricity of the foundation (e) is defined as the distance between point load and the center of foundation. Different values of load amplitude $(25,75$ and 100$) \mathrm{kN}$ are applied at e/B $(0.1,0.2$ and 0.3$)$ from center of foundation with three values of foundation thickness $(0.3,0.5,0.75) \mathrm{m}$.

The eccentricity of the foundation is increased to (e/B $=0.1,0.2$, and 0.3 ) to study its effect on the distribution of displacements and stresses. The results are summarized in Figures 3 to 17. From Figures 4 to 11, it is noticed that the settlement takes place on one side of foundation and upward displacement on the other side with increasing the eccentricity to $(0.2$ and 0.3$)$ and this is due to the vertical displacement which acts to push the soil under loading causing an uplift at the farther side. It is also observed that in these figures, with the presence of eccentricity, the maximum vertical displacement will turn aside from center of foundation because the maximum vertical displacement will happen under the point of load application.

From Figures 12 to 17 , it noticed that the larger thickness with eccentricity (e/B $=0.3$ ) causes a stiff behavior (more rigidity), and the oscillation of stress becomes smaller.

From Figure 12, it is noticed that the oscillation of stress for the farther points from point load increases greater than the nearer points. This is because the foundation length on the other side increases making the foundation behave as a long cantilever beam.

From Figures 3 a to 5 a, it can be noticed that when the load eccentricity increases from (e/B $=0.1$ to 0.2 and 0.3$)$ for amplitude loads $(\mathrm{p}=25,75$ and 100$) \mathrm{kN}$ and in case of $\mathrm{t}=0.3 \mathrm{~m}$, the maximum vertical displacement at node (81) in the center of foundation increases by about $(0.05,0.7$ and 20.5$) \%$, respectively.

On the other hand, from Figures 12 to 14 , it can be seen that when the load eccentricity increases from ( $\mathrm{e} / \mathrm{B}=0.1$ to 0.2 and 0.3 ) for amplitude loads $(\mathrm{p}=25,75$ and 100$) \mathrm{kN}$ and in case of $\mathrm{t}=0.3 \mathrm{~m}$, the maximum vertical stress at node $(81)$ decreases by about $(22.7,28.2$ and 29.7$) \%$, respectively.

From Figures 6 a to 8 a, it can be concluded that when the load eccentricity increases from (e/B $=0.1$ to 0.2 and 0.3 ) for amplitude loads $(\mathrm{p}=25,75$ and 100$) \mathrm{kN}$ and in case of $\mathrm{t}=0.5 \mathrm{~m}$, the ratio of maximum vertical displacement at e/B of $(0.1,0.2$ and 0.3$)$ to maximum vertical displacement at no load eccentricity $(\mathrm{e} / \mathrm{B}=0)$ increases 
by about $(1.4,32.4$ and 87$) \%$, respectively. On the other hand, from Figures 15 a to 17 $\mathrm{a}$, it can be seen that when the load eccentricity increases from $(\mathrm{e} / \mathrm{B}=0.1$ to 0.2 and 0.3 ) for amplitude loads ( $\mathrm{p}=25,75$ and 100) $\mathrm{kN}$ and in case of $\mathrm{t}=0.5 \mathrm{~m}$, the maximum vertical stress at node (81) decreases by about (4, 9.6 and 10.8) \%, respectively.

From Figures 9 a to 11 a, it can be noticed that when the load eccentricity increases from ( $/ \mathrm{B}=0.1$ to 0.2 and 0.3$)$ for amplitude loads $(\mathrm{p}=25,75$ and 100$) \mathrm{kN}$ and in case of $\mathrm{t}=0.75 \mathrm{~m}$, the ratio of maximum vertical displacement at $\mathrm{e} / \mathrm{B}$ of $(0.1,0.2$ and $0.3)$ to maximum vertical displacement at no load eccentricity $(\mathrm{e} / \mathrm{B}=0)$ increases by about (11.6, 52.3 and 111.5$) \%$, respectively.

On the other hand for, it can be noted that when the load eccentricity increases from $(\mathrm{e} / \mathrm{B}=0.1$ to 0.2 and 0.3$)$ for amplitude loads $(\mathrm{p}=25,75$ and 100) $\mathrm{kN}$ and in case of $\mathrm{t}=0.75 \mathrm{~m}$, the maximum vertical stress at node $(81)$ decreases by about $(2.3,4.3$ and 10.6$) \%$, respectively.

From Figure 3 a, the maximum vertical displacement takes place at time $(0.24 \mathrm{sec}$. $)$ for $(\mathrm{e} / \mathrm{B}=0.1)$, thickness $(0.3 \mathrm{~m})$ and amplitude loads $(25,75$ and 100$) \mathrm{kN}$, while the maximum vertical displacement occurs at time $(0.45 \mathrm{sec}$.$) for (\mathrm{e} / \mathrm{B}=0.1)$, thickness $(0.5$ m) under the same loads, Figure 6 a.

From Figures 7 a and 8 a, the maximum vertical displacement takes place at time $(0.49 \mathrm{sec}$.$) for (\mathrm{e} / \mathrm{B}=0.1$ and $\mathrm{e} / \mathrm{B}=0.2)$, thickness $(0.75 \mathrm{~m})$ and amplitude loads $(25,75$ and 100$) \mathrm{kN}$. Also, it can be seen that the maximum vertical displacement takes place at time $(0.5 \mathrm{sec}$.$) for (\mathrm{e} / \mathrm{B}=0.2)$ and the thickness $(0.3$ and 0.5$) \mathrm{m}$ and loads $\quad(25,75$ and 100) $\mathrm{kN}$, Figures 4 a and 7 a.

On the other hand, the maximum vertical displacement occurs at time $(0.5 \mathrm{sec}$.) for $(\mathrm{e} / \mathrm{B}=0.3)$ and thickness $(0.3,0.5$ and 0.75$) \mathrm{m}$ and loads $(25,75$ and 100$) \mathrm{kN}$, Figures 5 a, 8 a and 11 a, respectively. From Figure 12 a, the maximum vertical stress takes place at time $(0.23 \mathrm{sec}$.$) for (\mathrm{e} / \mathrm{B}=0.1)$, thickness $(0.3 \mathrm{~m})$ and amplitude loads $(25,75$ and 100) $\mathrm{kN}$, while the maximum vertical stress occurs at time $(0.26 \mathrm{sec}$. $)$ for $(\mathrm{e} / \mathrm{B}=0.2)$, thickness $(0.3 \mathrm{~m})$ and the same loads, Figure 13 a. Also, it can be seen that the maximum vertical stress occurs at time $(0.16 \mathrm{sec}$. ) for $(\mathrm{e} / \mathrm{B}=0.3)$, thickness $(0.3 \mathrm{~m})$ and the same loads, Figure 14 a. From Figure 15 a, the maximum vertical stress takes place at time $(0.37 \mathrm{sec}$.$) for (\mathrm{e} / \mathrm{B}=0.1)$, thickness $(0.5 \mathrm{~m})$ and amplitude loads $(25,75$ and 100$) \mathrm{kN}$, while the maximum vertical stress occurs at time $(0.14 \mathrm{sec}$.) for $(\mathrm{e} / \mathrm{B}=0.2)$, thickness $(0.5 \mathrm{~m})$ and the same loads, Figure 16 a. Also, it can be noticed that the maximum vertical stress occurs at time $(0.37 \mathrm{sec}$.$) for (\mathrm{e} / \mathrm{B}=0.3)$, thickness $(0.5$ $\mathrm{m})$ and the same loads, Figure 17 a.

These figures reveal that increasing the load eccentricity from $\mathrm{e} / \mathrm{B}=0.1$ to 0.2 and 0.3 results in increasing the maximum displacement and reducing the maximum stress. This is due to non-uniformly distributed stresses on the loaded area, where the loads are locally concentrated within the loaded area, and this leads to increase the stresses in this area and decrease it in other area, this difference in concentration of loads leads to decrease the vertical stress [23-24]. 


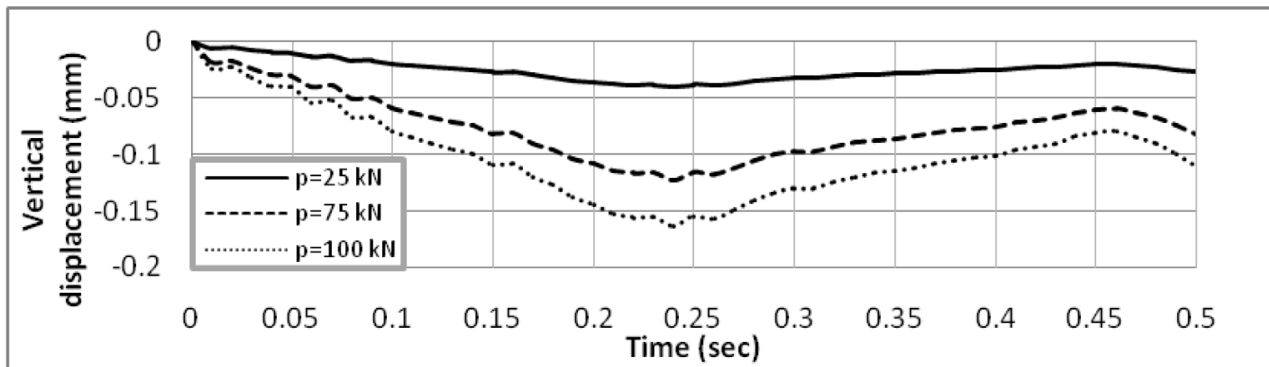

a) at node 81 (center of foundation)

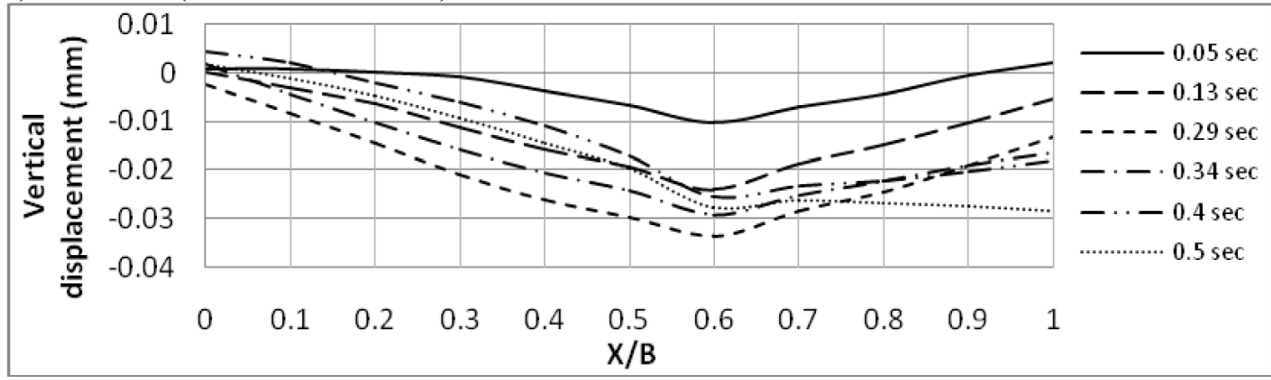

b) along section a-a (for amplitude $25 \mathrm{kN}$ )

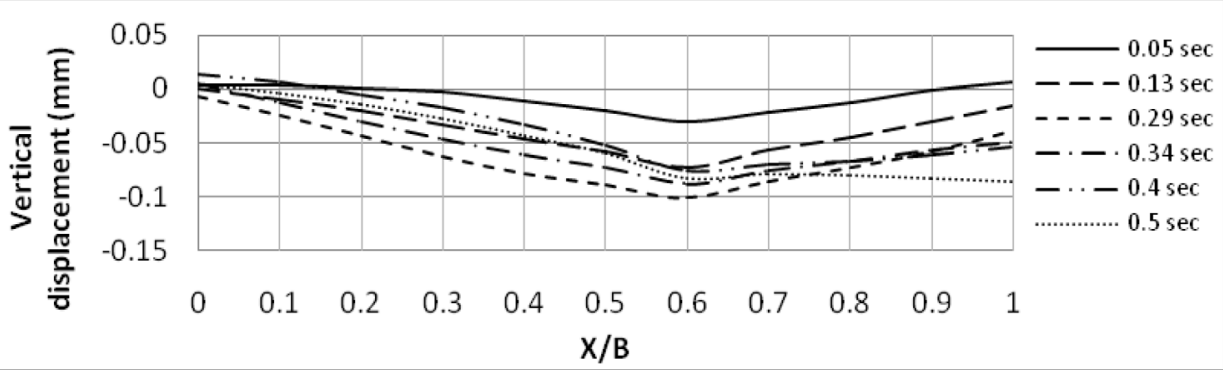

c) along section a-a (for amplitude $75 \mathrm{kN}$ )

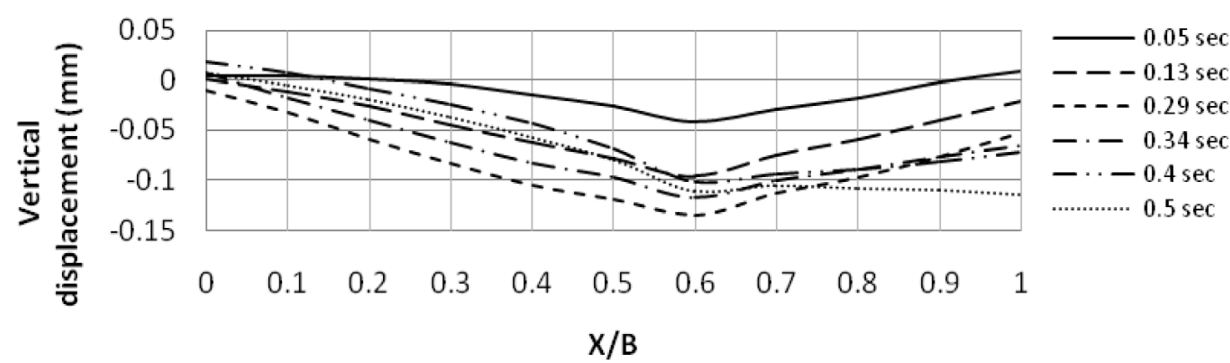

d) along section a-a (for amplitude $100 \mathrm{kN}$ )

Fig. 3: Dynamic response of the foundation to impact load, vertical displacement, $t=0.3 \mathrm{~m}, \mathrm{~B}=3 \mathrm{~m}$, $\mathrm{L}=3 \mathrm{~m}, \mathrm{e} / \mathrm{B}=0.1, \mathrm{D}=0$. 


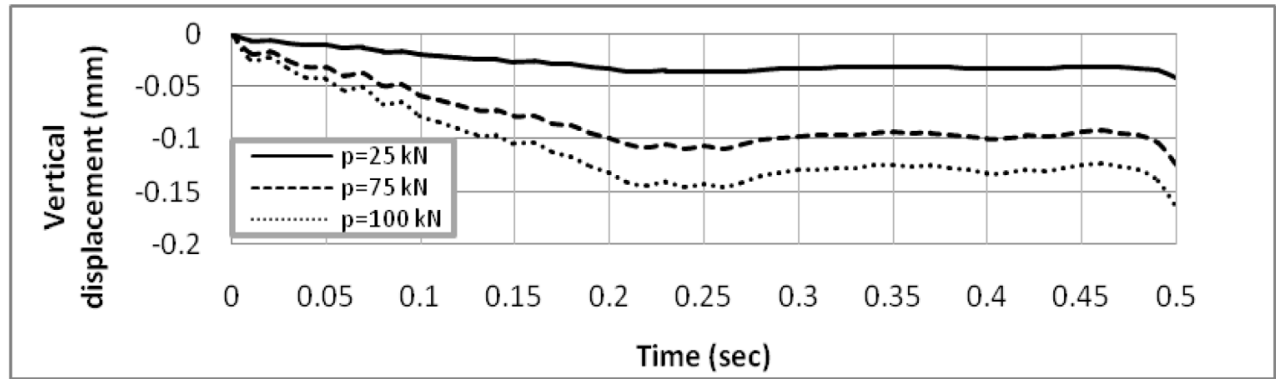

a) at node 81 (center of foundation)

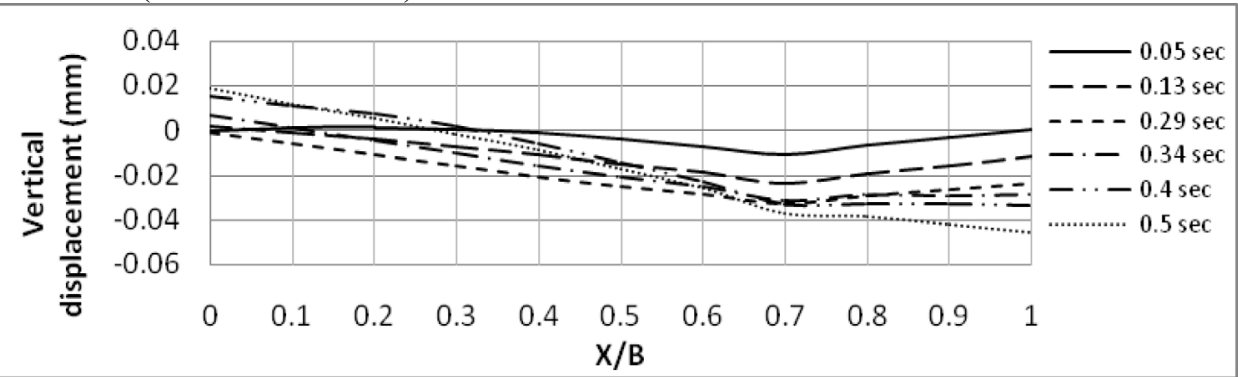

b) along section a-a (for amplitude $25 \mathrm{kN}$ )

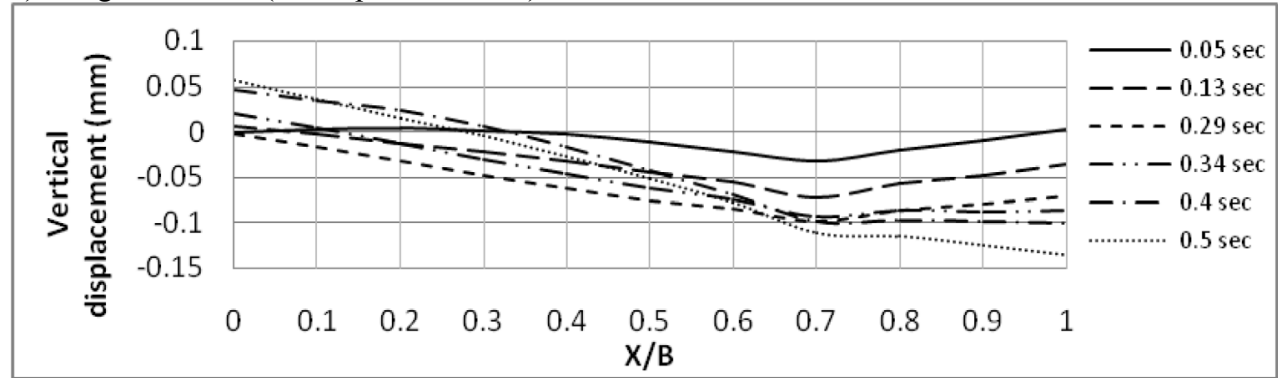

c) along section a-a (for amplitude $75 \mathrm{kN}$ )

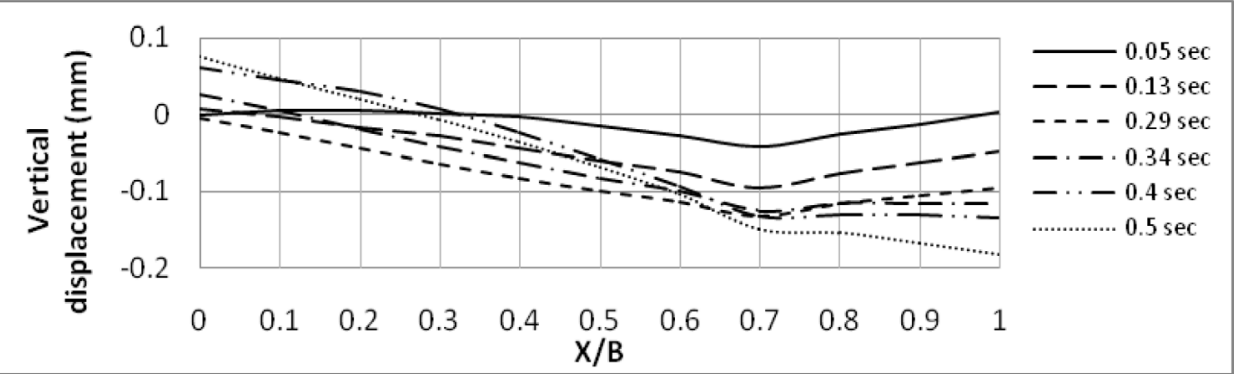

d) along section a-a (for amplitude $100 \mathrm{kN}$ )

Fig. 4: Dynamic response of the foundation to impact load, vertical displacement, $t=0.3 \mathrm{~m}, \mathrm{~B}=3 \mathrm{~m}$, $\mathrm{L}=3 \mathrm{~m}, \mathrm{e} / \mathrm{B}=0.2, \mathrm{D}=0$. 


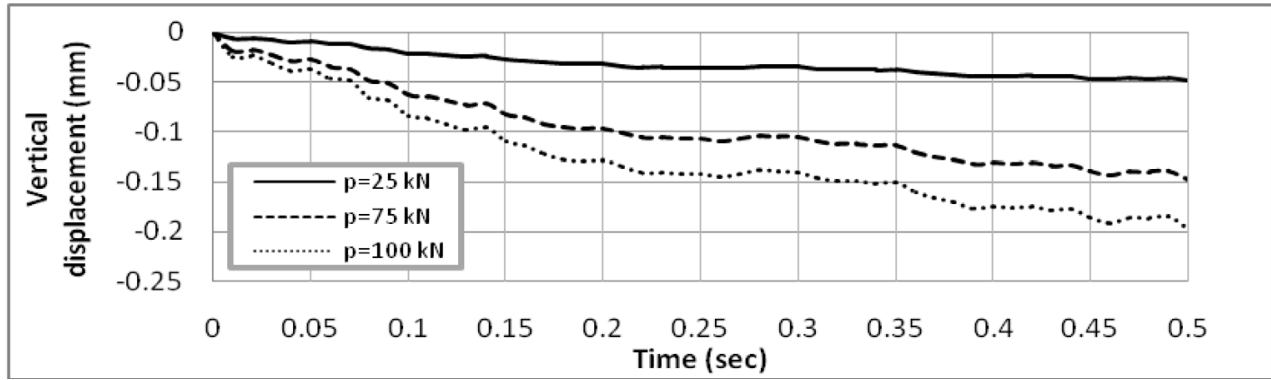

a) at node 81 (center of foundation)

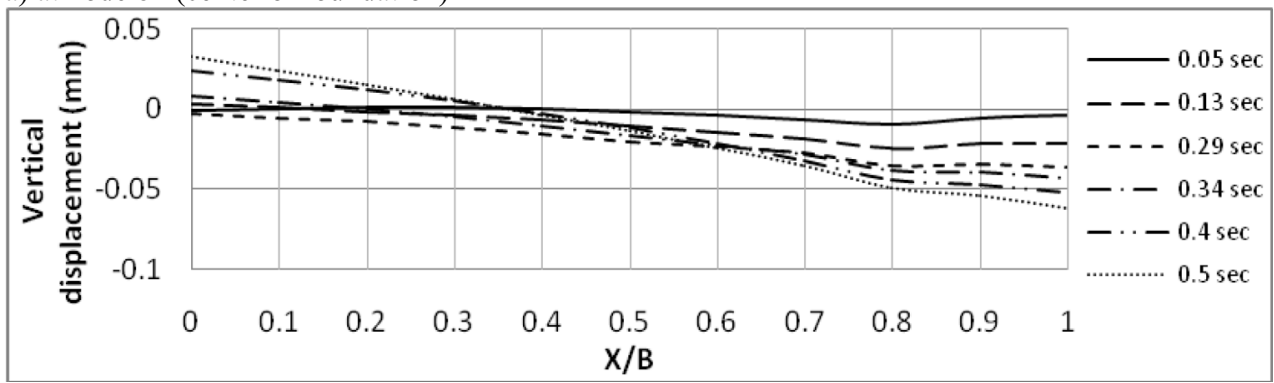

b) along section a-a (for amplitude $25 \mathrm{kN}$ )

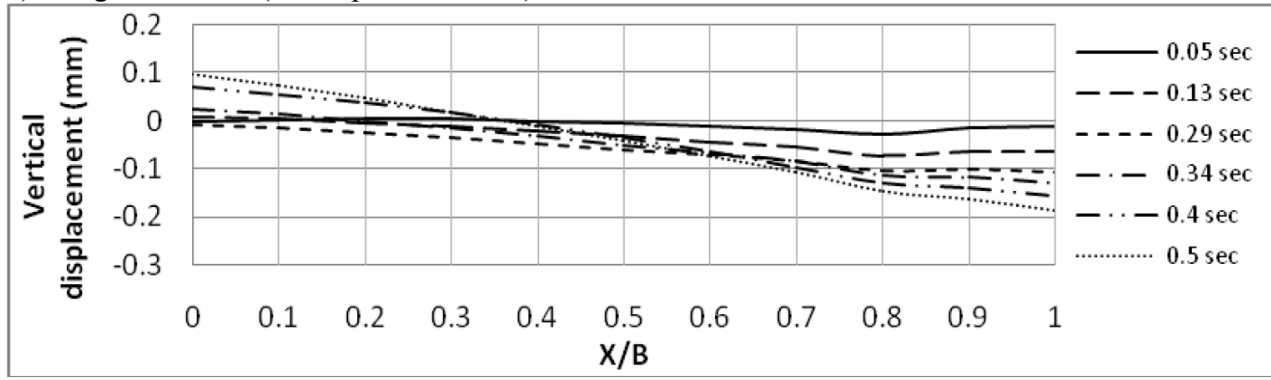

c) along section a-a (for amplitude $75 \mathrm{kN}$ )

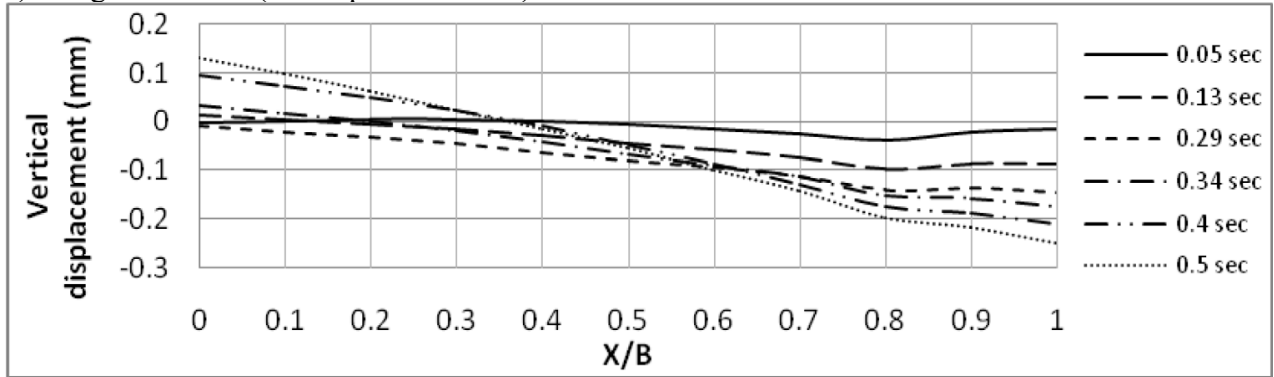

d) along section a-a (for amplitude $100 \mathrm{kN}$ )

Fig. 5: Dynamic response of the foundation to impact load, vertical displacement, $t=0.3 \mathrm{~m}, \mathrm{~B}=3 \mathrm{~m}$, $\mathrm{L}=3 \mathrm{~m}, \mathrm{e} / \mathrm{B}=0.3, \mathrm{D}=0$. 


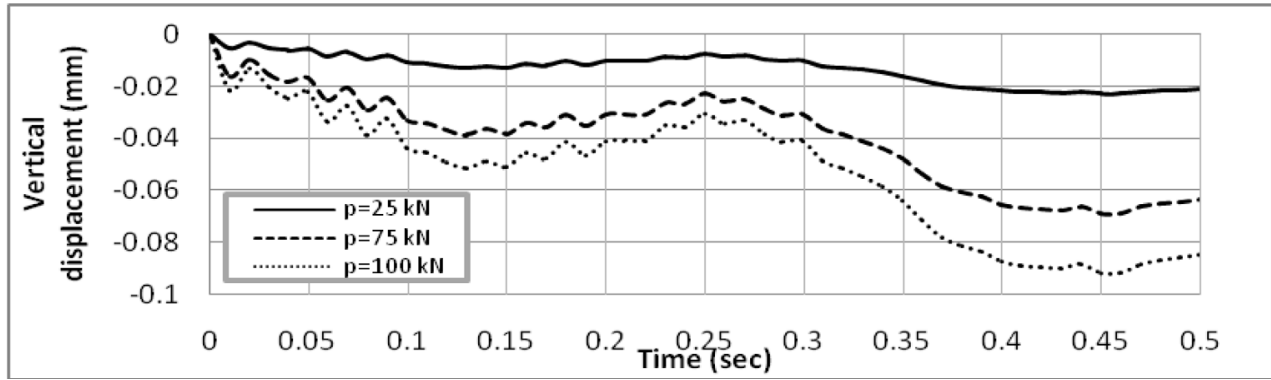

a) at node 81 (center of foundation)

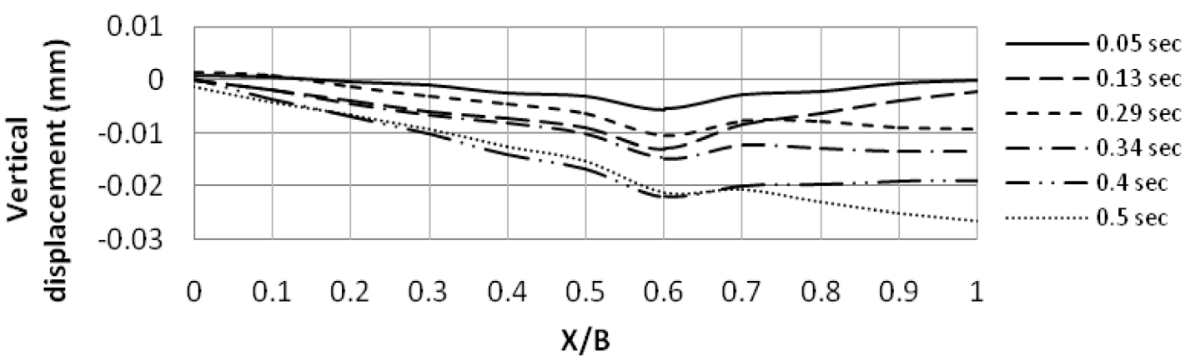

b) along section a-a (for amplitude $25 \mathrm{kN}$ )

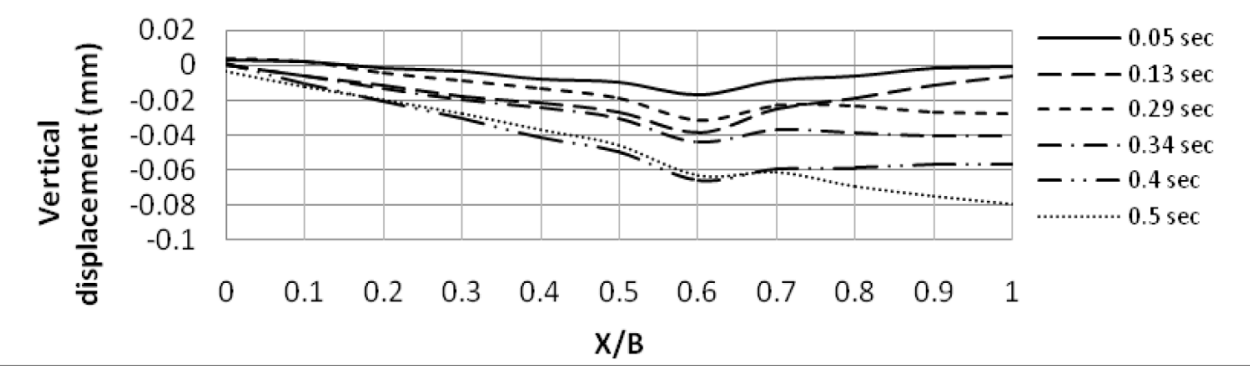

c) along section a-a (for amplitude $75 \mathrm{kN}$ )

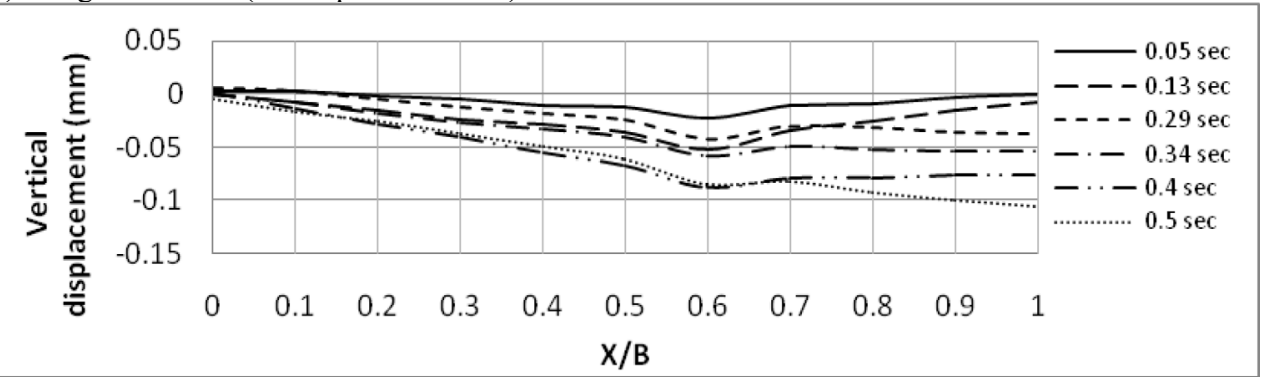

d) along section a-a (for amplitude $100 \mathrm{kN}$ )

Fig. 6: Dynamic response of the foundation to impact load, vertical displacement, $t=0.5 \mathrm{~m}, \mathrm{~B}=3 \mathrm{~m}$, $\mathrm{L}=3 \mathrm{~m}, \mathrm{e} / \mathrm{B}=0.1, \mathrm{D}=0$. 


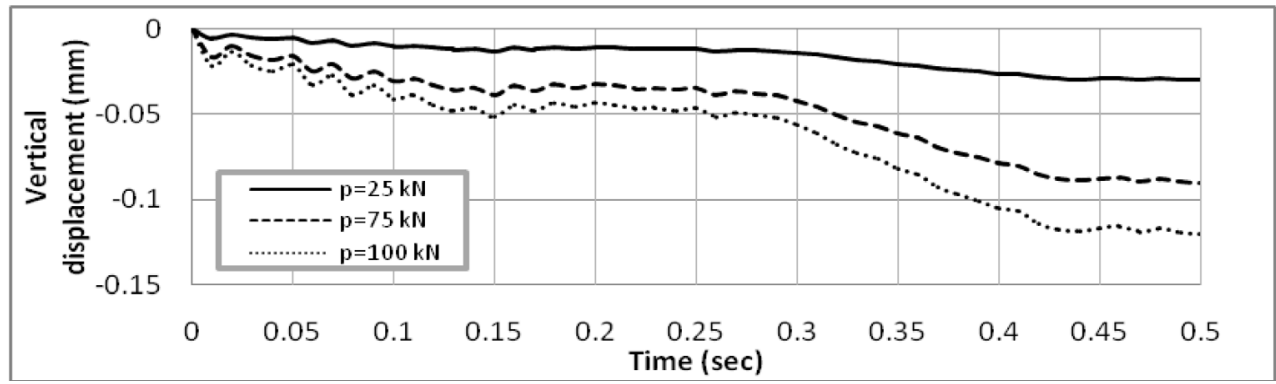

a) at node 81 (center of foundation)

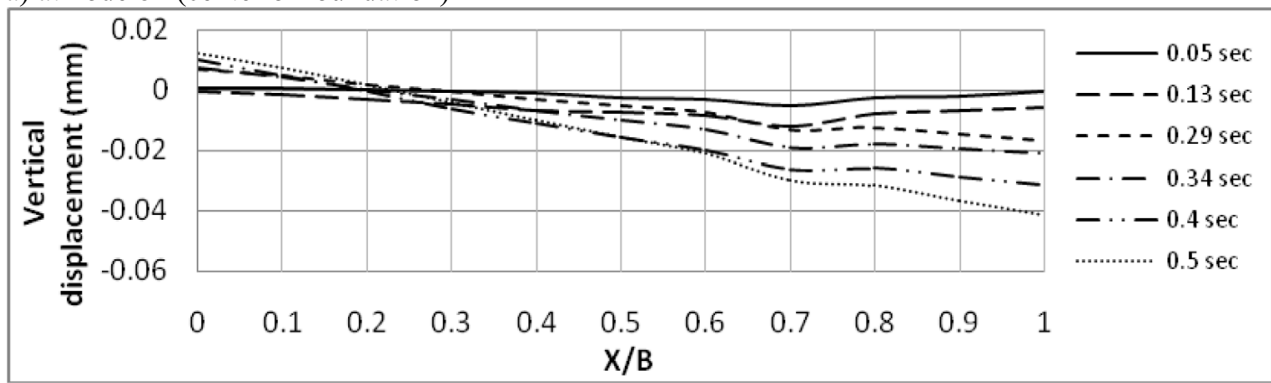

b) along section a-a (for amplitude $25 \mathrm{kN}$ )

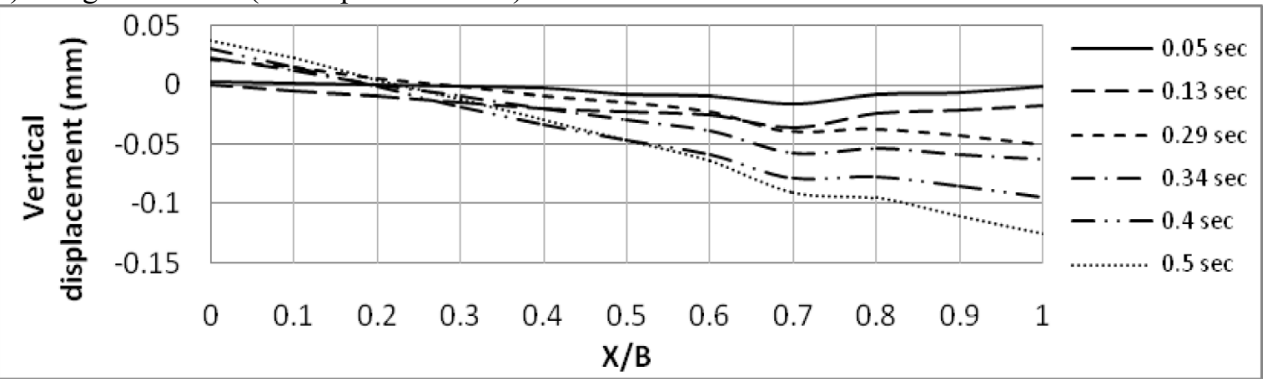

c) along section a-a (for amplitude $75 \mathrm{kN}$ )

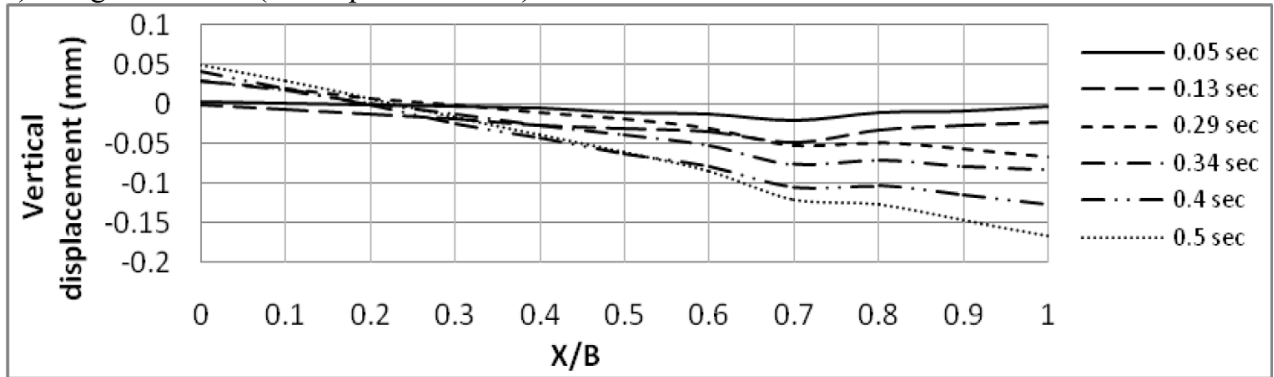

d) along section a-a (for amplitude $100 \mathrm{kN}$ )

Fig. 7: Dynamic response of the foundation to impact load, vertical displacement, $t=0.5 \mathrm{~m}, \mathrm{~B}=3 \mathrm{~m}$, $\mathrm{L}=3 \mathrm{~m}, \mathrm{e} / \mathrm{B}=0.2, \mathrm{D}=0$. 


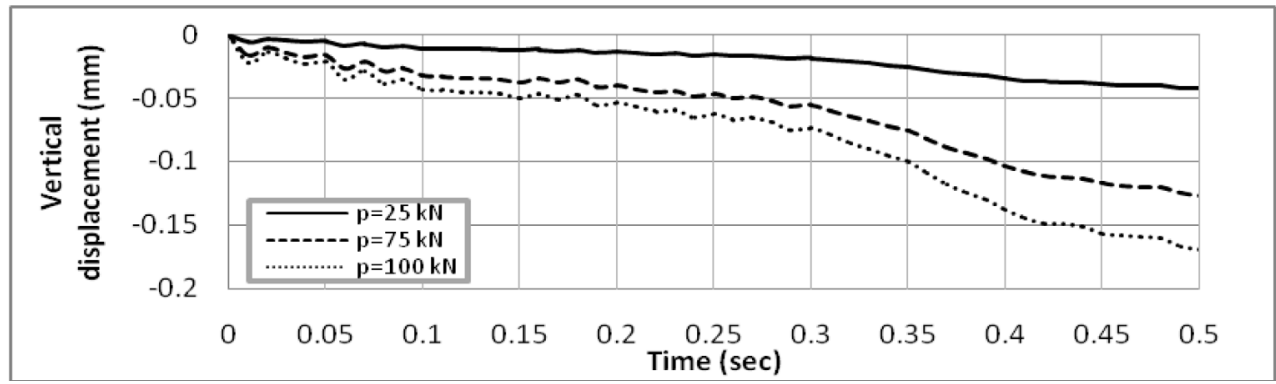

a) at node 81 (center of foundation)

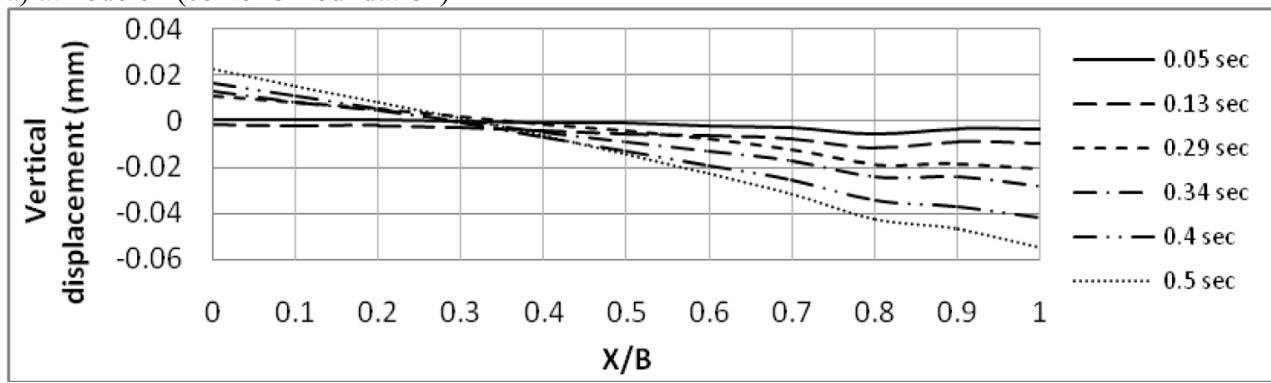

b) along section a-a (for amplitude $25 \mathrm{kN}$ )

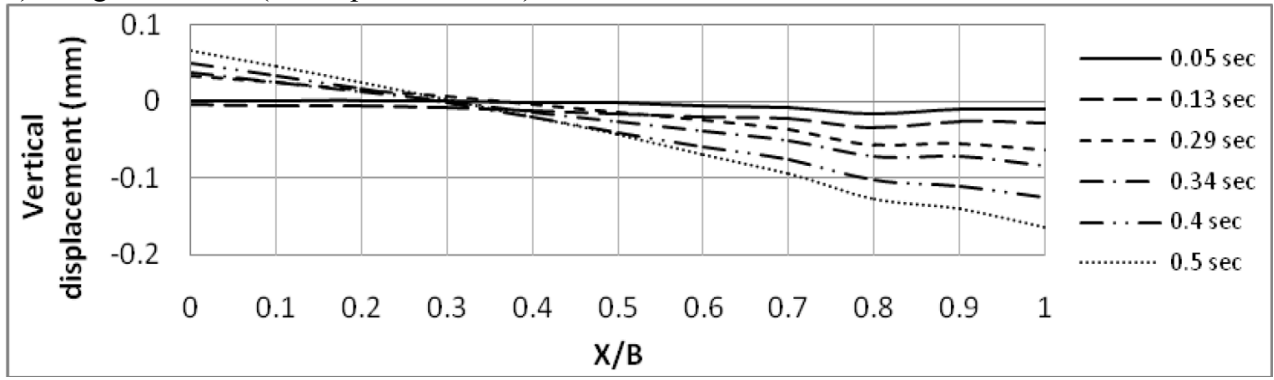

c) along section a-a (for amplitude $75 \mathrm{kN}$ )

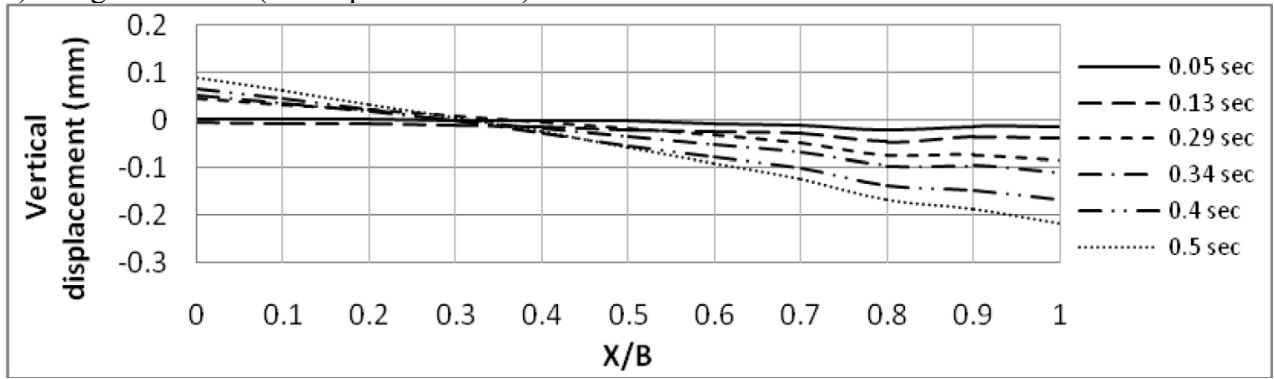

d) along section a-a (for amplitude $100 \mathrm{kN}$ )

Fig. 8: Dynamic response of the foundation to impact load, vertical displacement, $t=0.5 \mathrm{~m}, \mathrm{~B}=3 \mathrm{~m}$, $\mathrm{L}=3 \mathrm{~m}, \mathrm{e} / \mathrm{B}=0.3, \mathrm{D}=0$. 


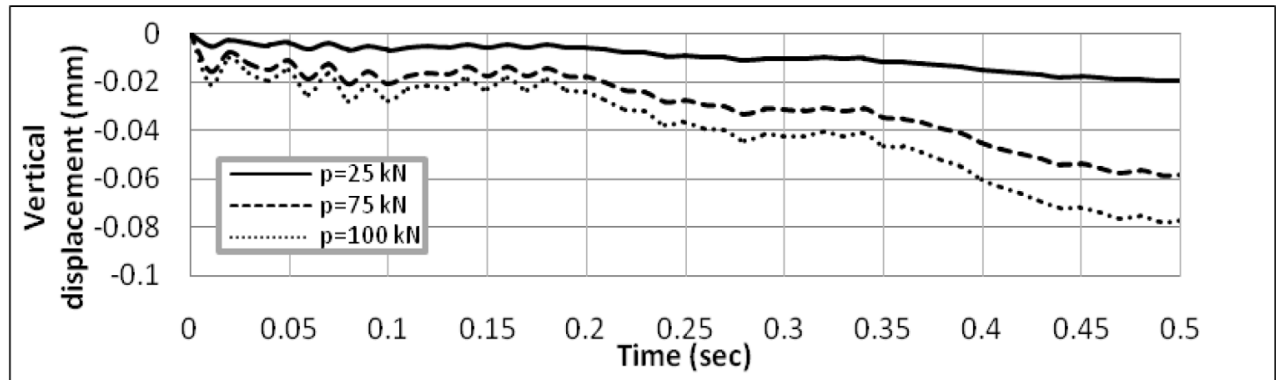

a) at node 81 (center of foundation)

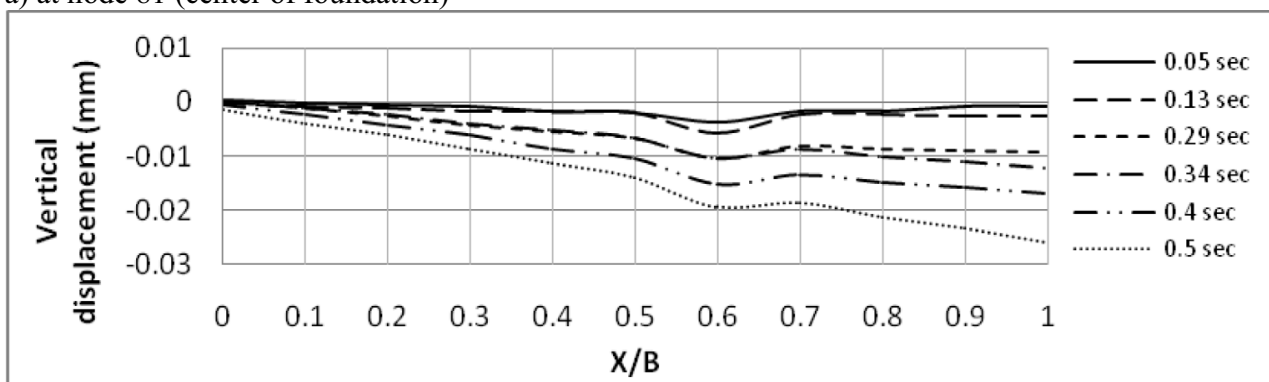

b) along section a-a (for amplitude $25 \mathrm{kN}$ )

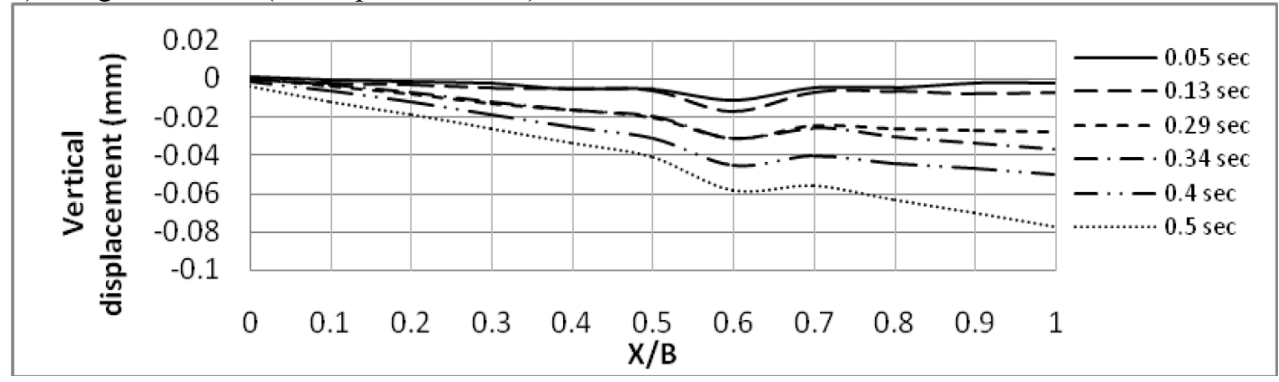

c) along section a-a (for amplitude $75 \mathrm{kN}$ )

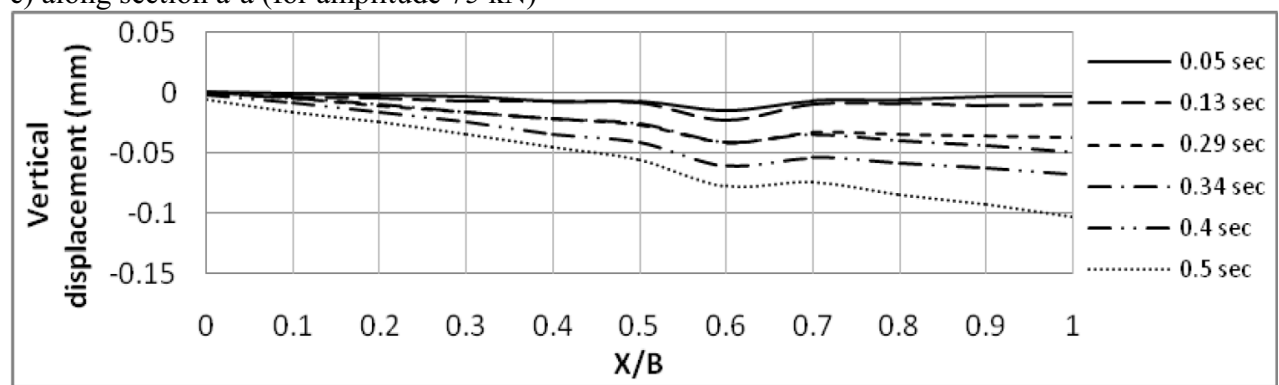

d) along section a-a (for amplitude $100 \mathrm{kN}$ )

Fig. 9: Dynamic response of the foundation to impact load, vertical displacement, $t=0.75 \mathrm{~m}, \mathrm{~B}=3 \mathrm{~m}$, $\mathrm{L}=3 \mathrm{~m}, \mathrm{e} / \mathrm{B}=0.1, \mathrm{D}=0$. 


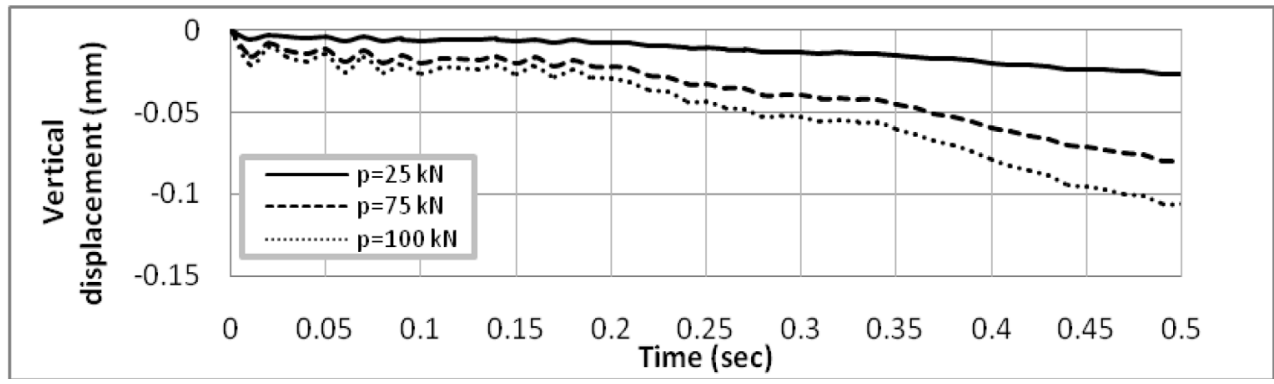

a) at node 81 (center of foundation)

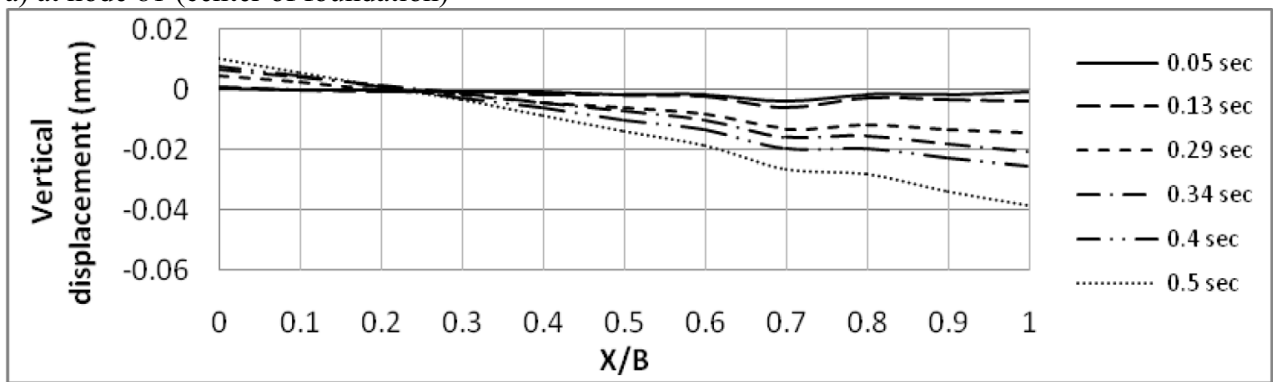

b) along section a-a (for amplitude $25 \mathrm{kN}$ )

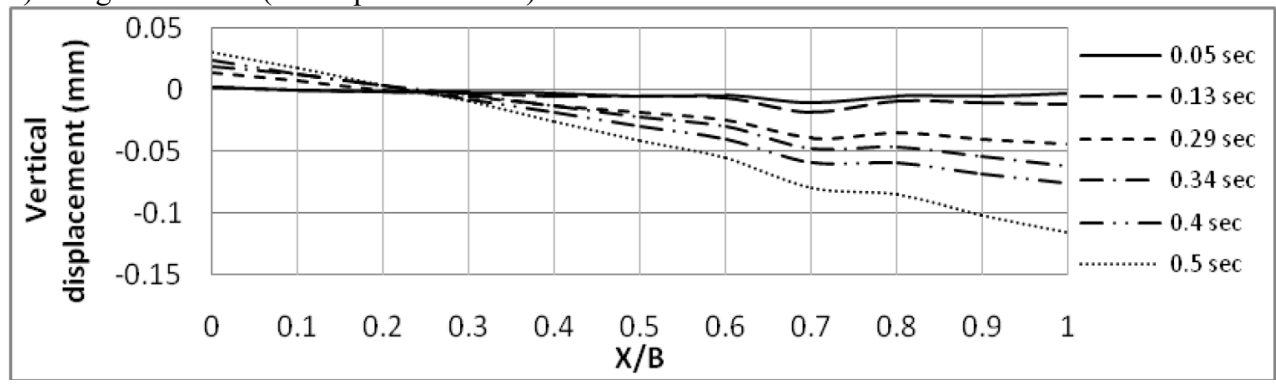

c) along section a-a (for amplitude $75 \mathrm{kN}$ )

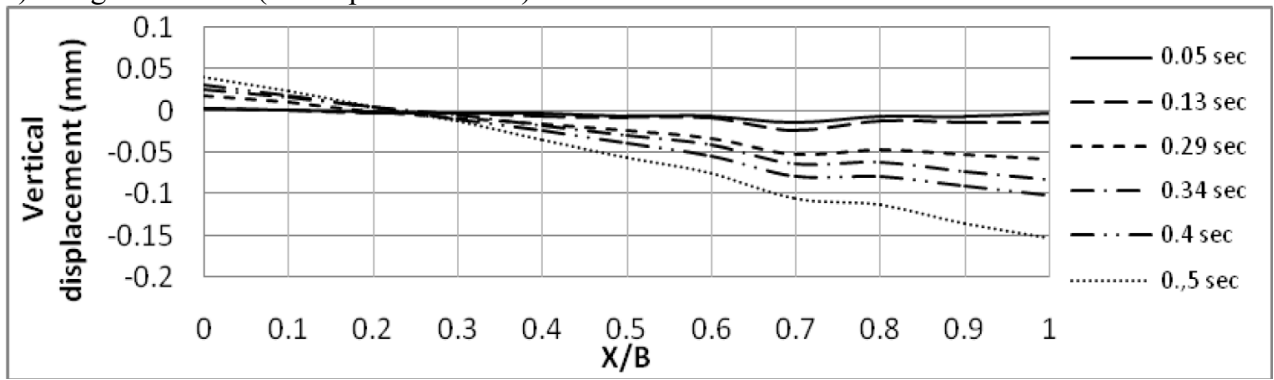

d) along section a-a (for amplitude $100 \mathrm{kN}$ )

Fig. 10: Dynamic response of the foundation to impact load, vertical displacement, $t=0.75 \mathrm{~m}, \mathrm{~B}=3 \mathrm{~m}$, $\mathrm{L}=3 \mathrm{~m}, \mathrm{e} / \mathrm{B}=0.2, \mathrm{D}=0$. 


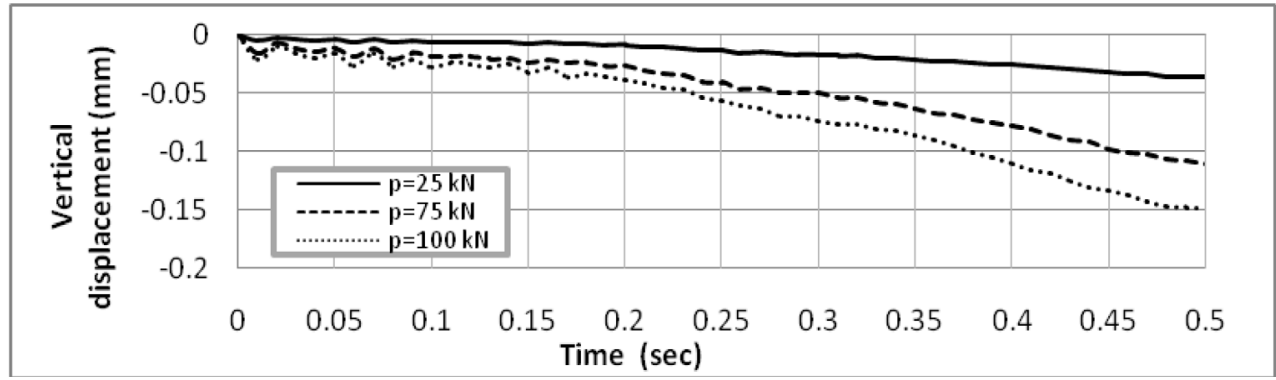

a) at node 81 (center of foundation)

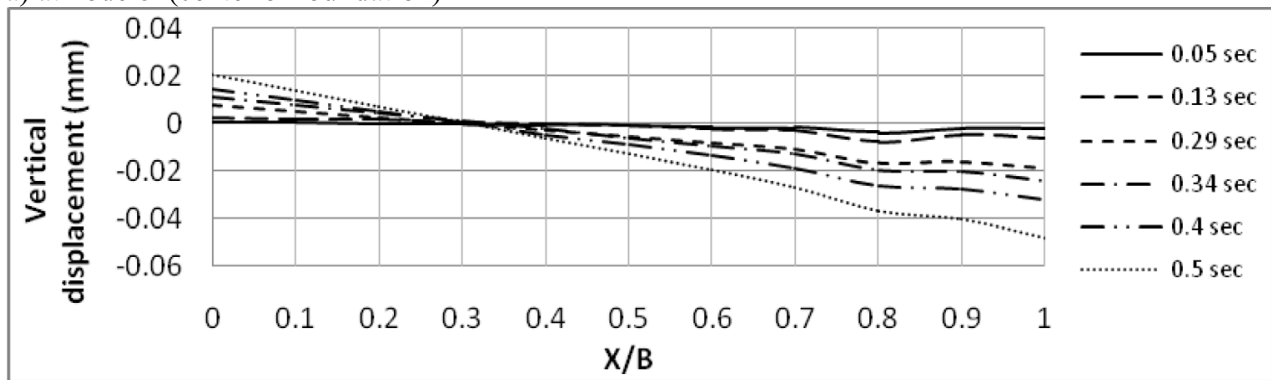

b) along section a-a (for amplitude $25 \mathrm{kN}$ )

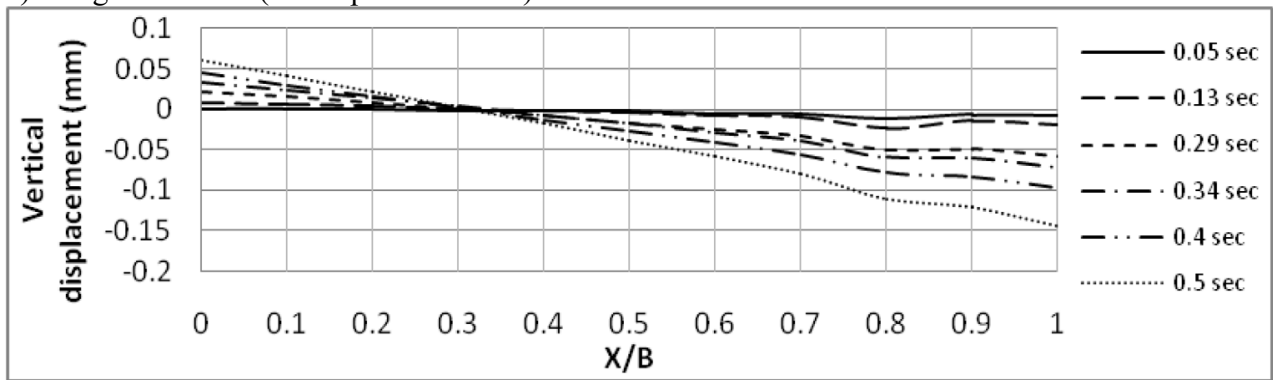

c) along section a-a (for amplitude $75 \mathrm{kN}$ )

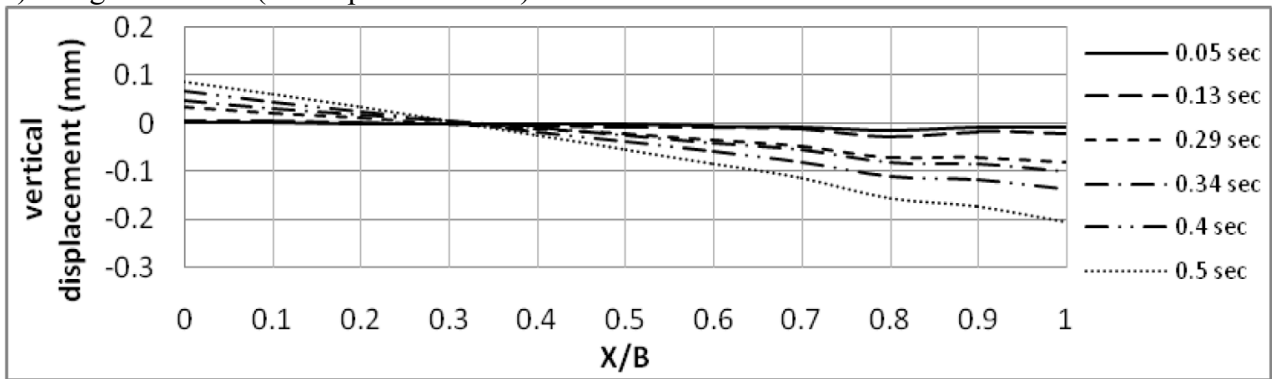

d) along section a-a (for amplitude $100 \mathrm{kN}$ )

Fig. 11: Dynamic response of the foundation to impact load, vertical displacement, $t=0.75 \mathrm{~m}, \mathrm{~B}=3 \mathrm{~m}$, $\mathrm{L}=3 \mathrm{~m}, \mathrm{e} / \mathrm{B}=0.3, \mathrm{D}=0$. 


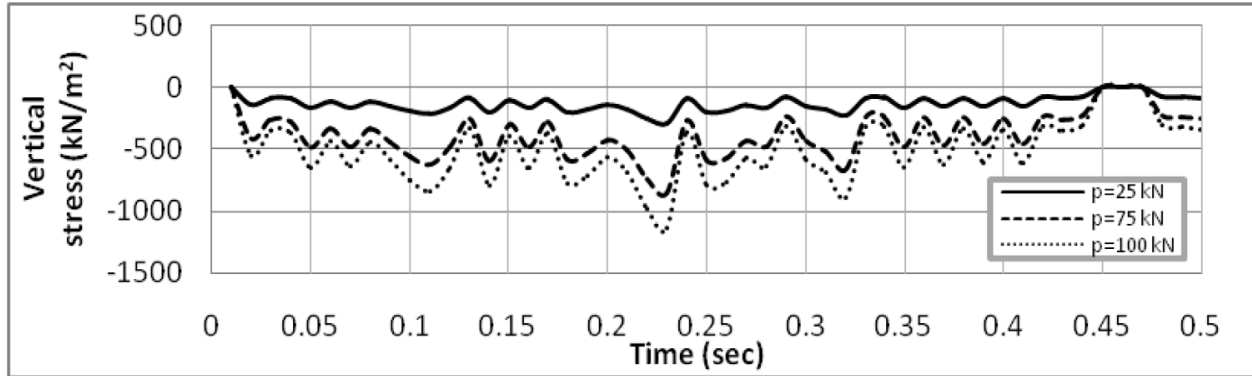

a) at node 81 (center of foundation)

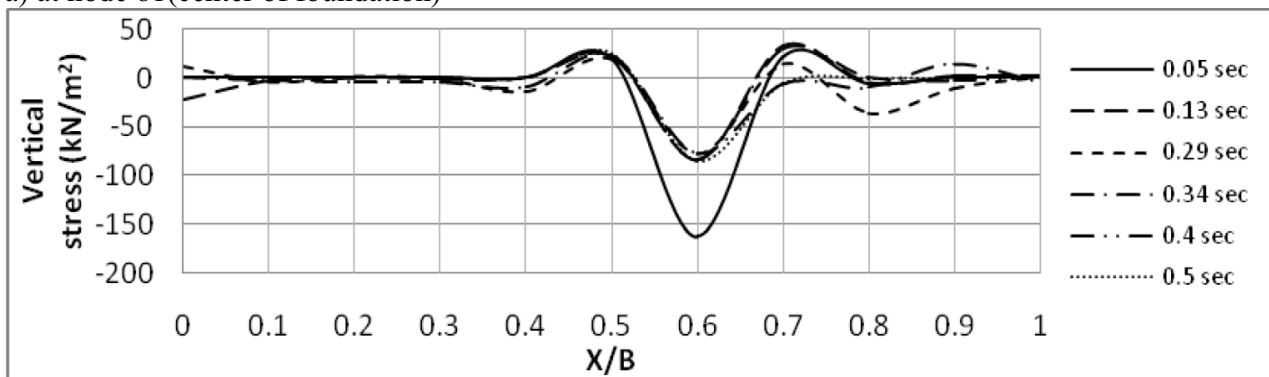

b) along section a-a (for amplitude $25 \mathrm{kN}$ )

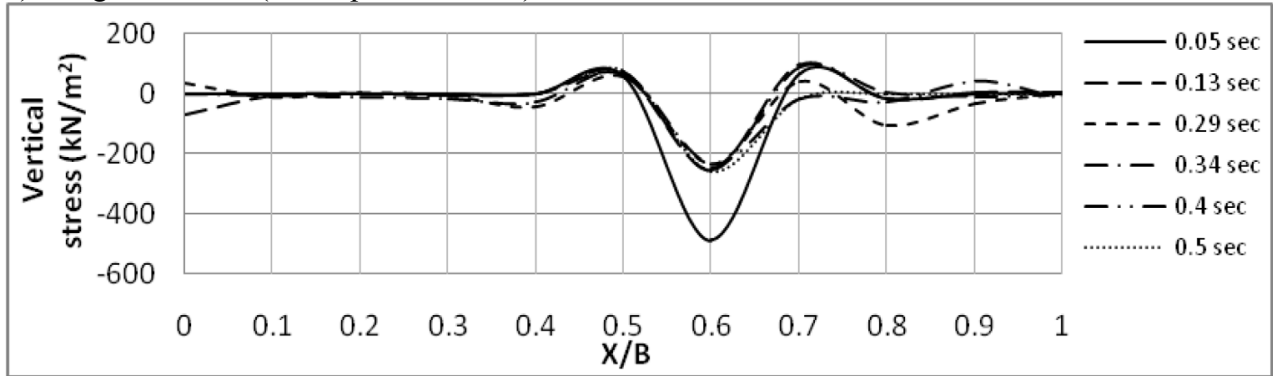

c) along section a-a (for amplitude $75 \mathrm{kN}$ )

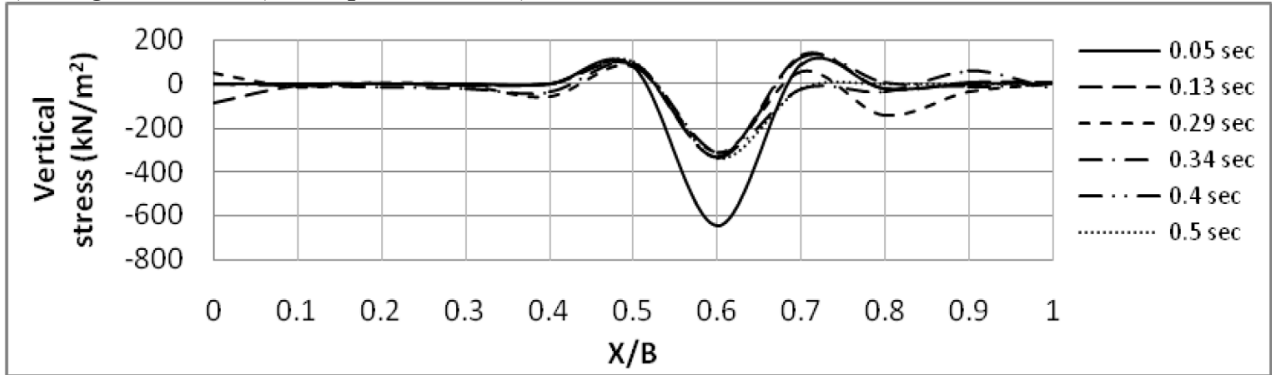

d) along section a-a (for amplitude $100 \mathrm{kN}$ )

Fig. 12: Dynamic response of the foundation to impact load, vertical stress, $t=0.3 \mathrm{~m}, \mathrm{~B}=3 \mathrm{~m}, \mathrm{~L}=3 \mathrm{~m}$, $\mathrm{e} / \mathrm{B}=0.1, \mathrm{D}=0$. 


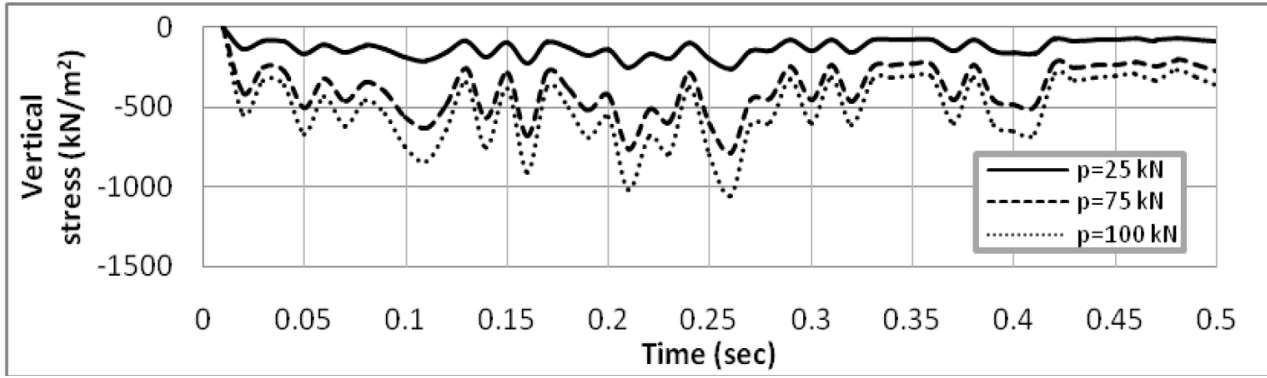

a) at node 81 (center of foundation)

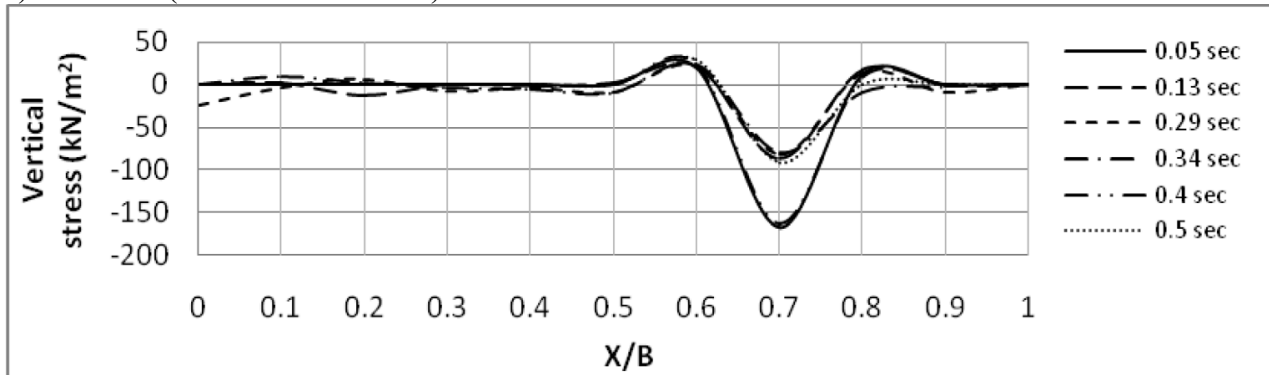

b) along section a-a (for amplitude $25 \mathrm{kN}$ )

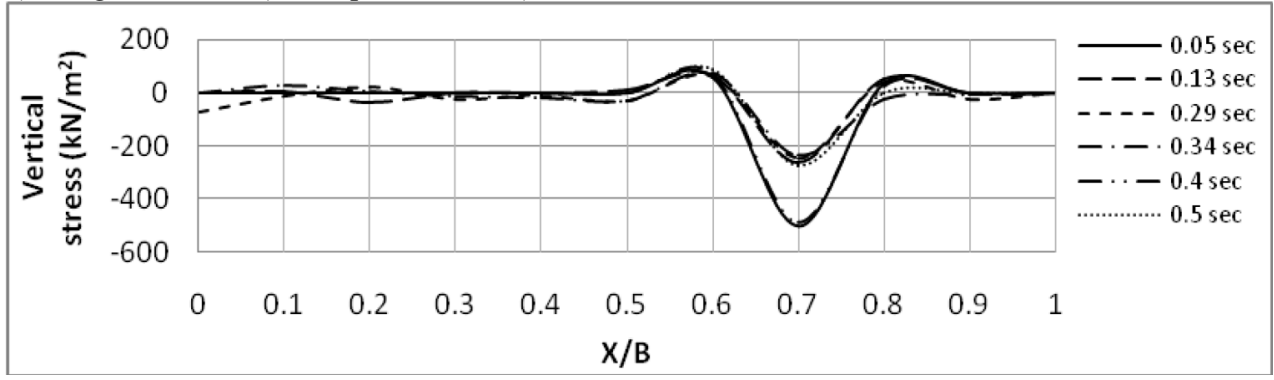

c) along section a-a (for amplitude $75 \mathrm{kN}$ )

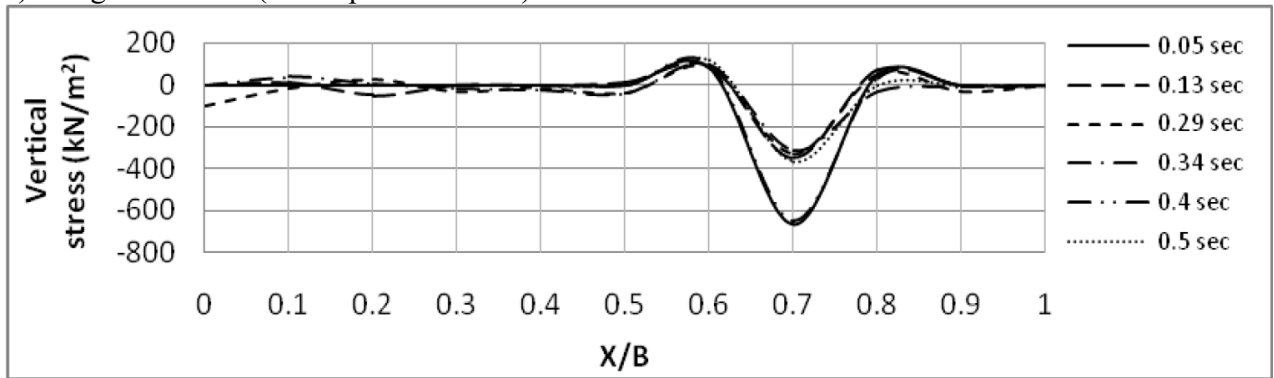

d) along section a-a (for amplitude $100 \mathrm{kN}$ )

Fig. 13: Dynamic response of the foundation to impact load, vertical stress, $t=0.3 \mathrm{~m}, \mathrm{~B}=3 \mathrm{~m}, \mathrm{~L}=3 \mathrm{~m}$, $\mathrm{e} / \mathrm{B}=0.2, \mathrm{D}=0$. 


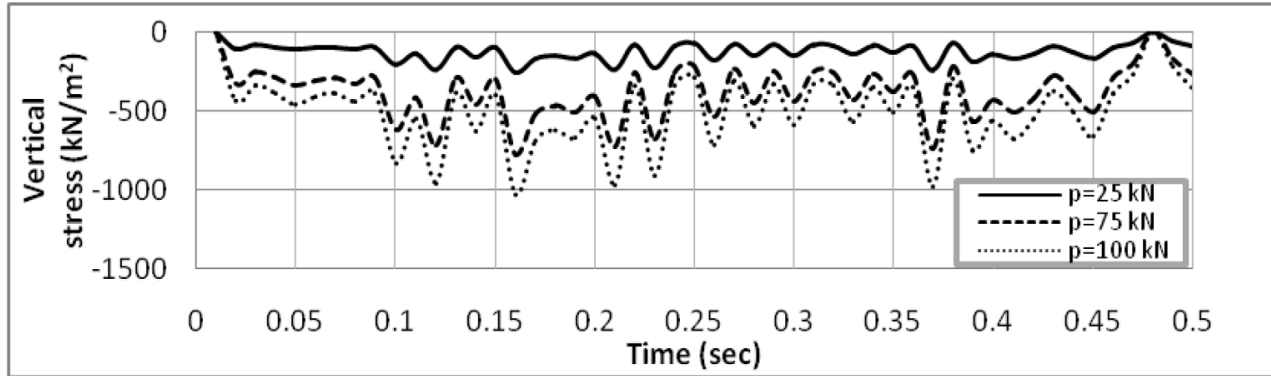

a) at node 81 (center of foundation)

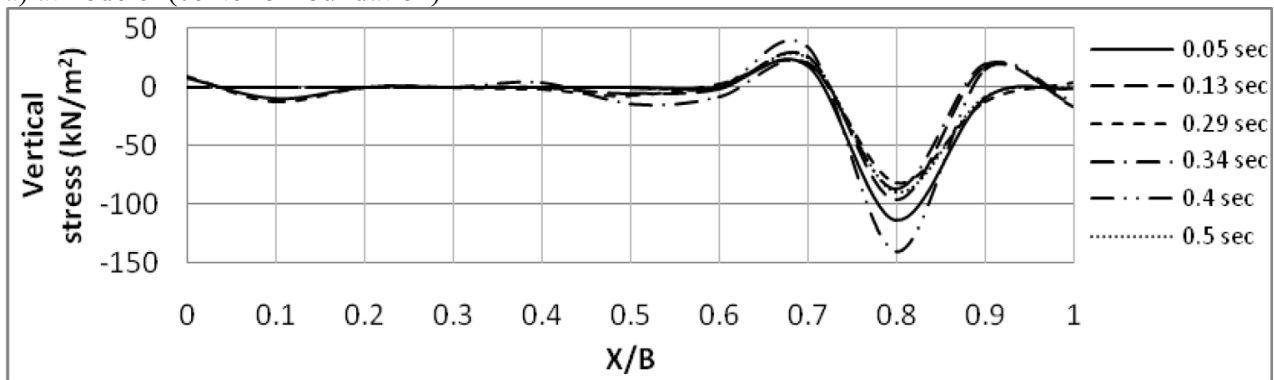

b) along section a-a (for amplitude $25 \mathrm{kN}$ )

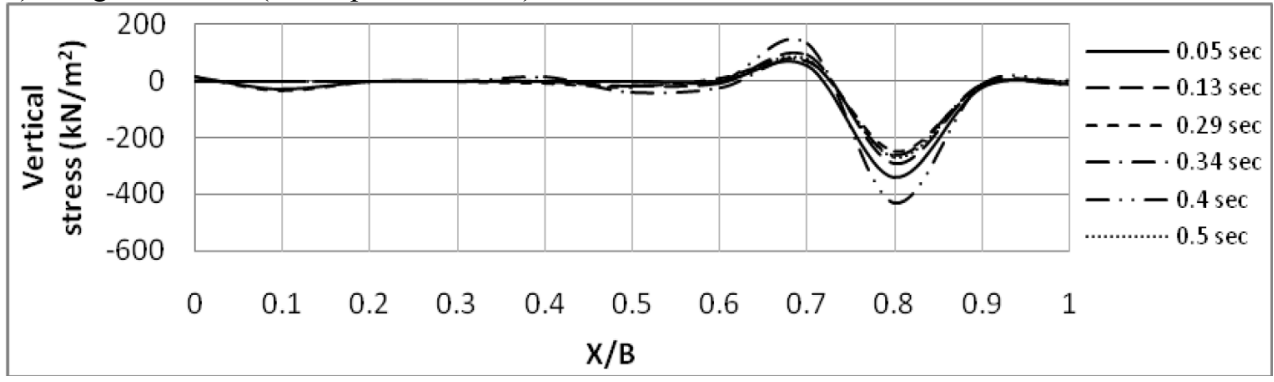

c) along section a-a (for amplitude $75 \mathrm{kN}$ )

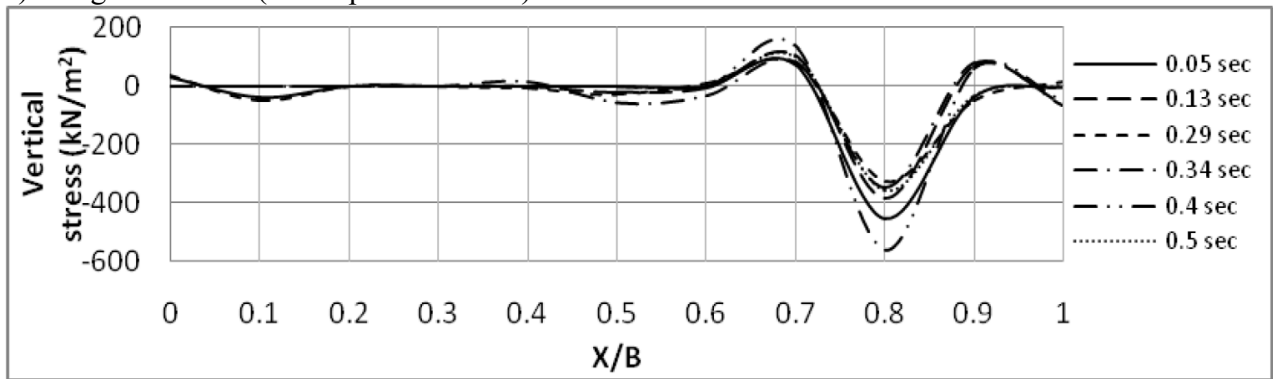

d) along section a-a (for amplitude $100 \mathrm{kN}$ )

Fig. 14: Dynamic response of the foundation to impact load, vertical stress, $t=0.3 \mathrm{~m}, B=3 \mathrm{~m}, \mathrm{~L}=3 \mathrm{~m}$, $\mathrm{e} / \mathrm{B}=0.3, \mathrm{D}=0$. 


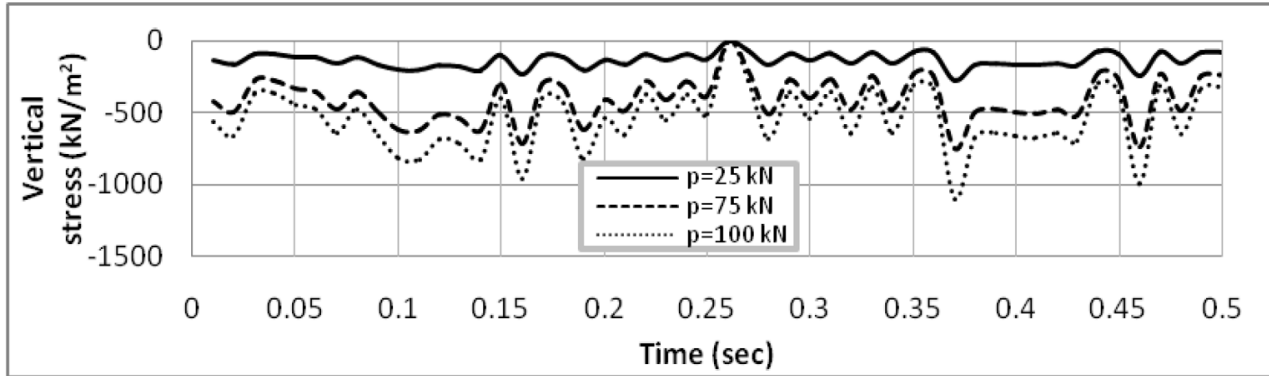

a) at node 81 (center of foundation)

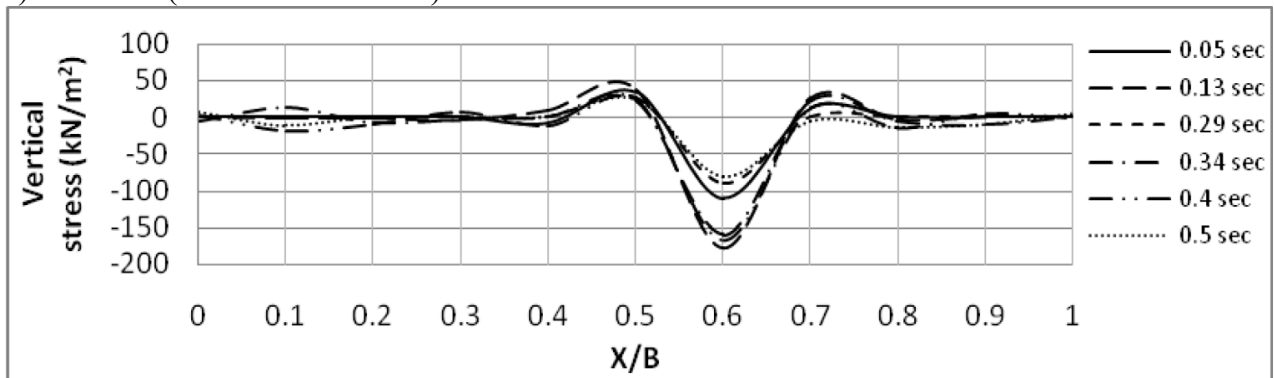

b) along section a-a (for amplitude $25 \mathrm{kN}$ )

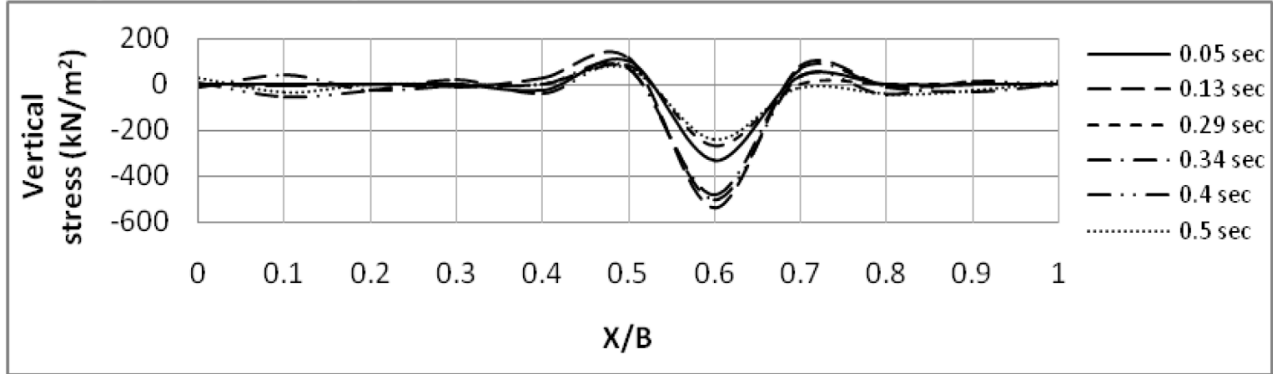

c) along section a-a (for amplitude $75 \mathrm{kN}$ )

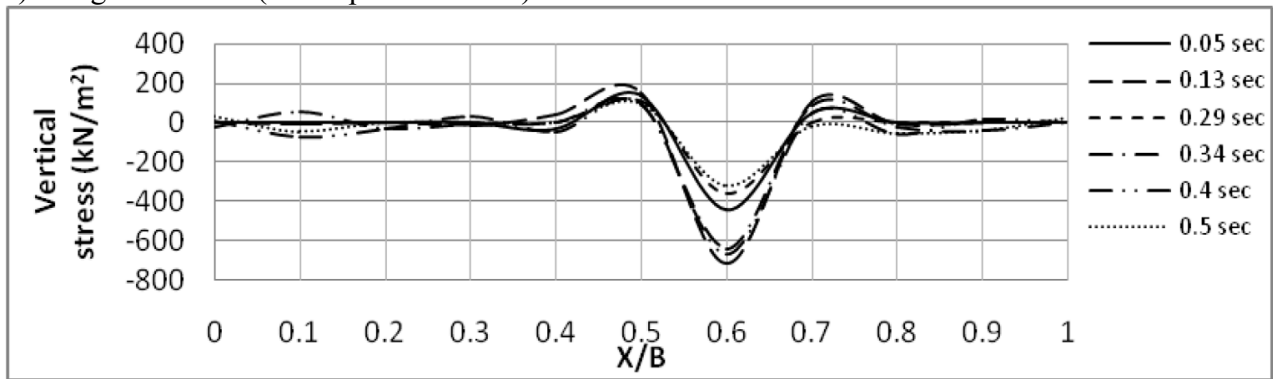

d) along section a-a (for amplitude $100 \mathrm{kN}$ )

Fig. 15: Dynamic response of the foundation to impact load, vertical stress, $t=0.5 \mathrm{~m}, \mathrm{~B}=3 \mathrm{~m}, \mathrm{~L}=3 \mathrm{~m}$, $\mathrm{e} / \mathrm{B}=0.1, \mathrm{D}=0$. 


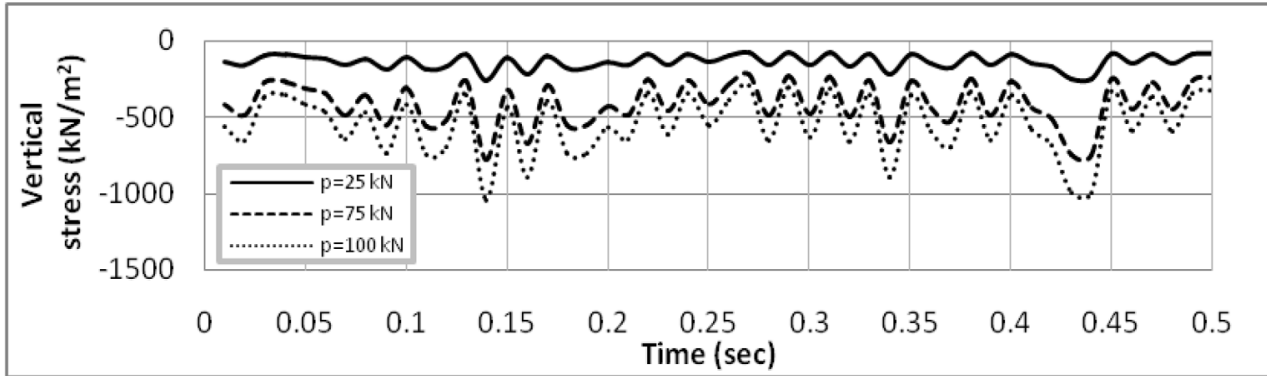

a) at node 81 (center of foundation)

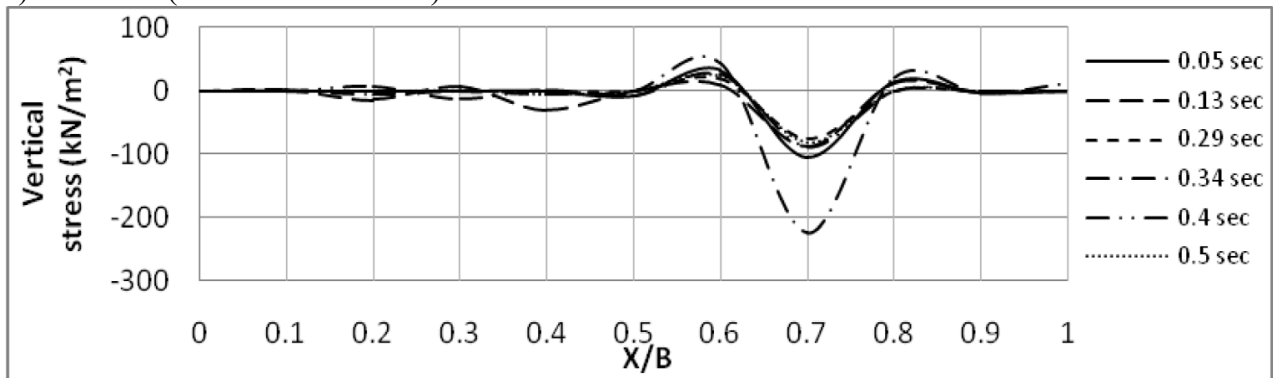

b) along section a-a (for amplitude $25 \mathrm{kN}$ )

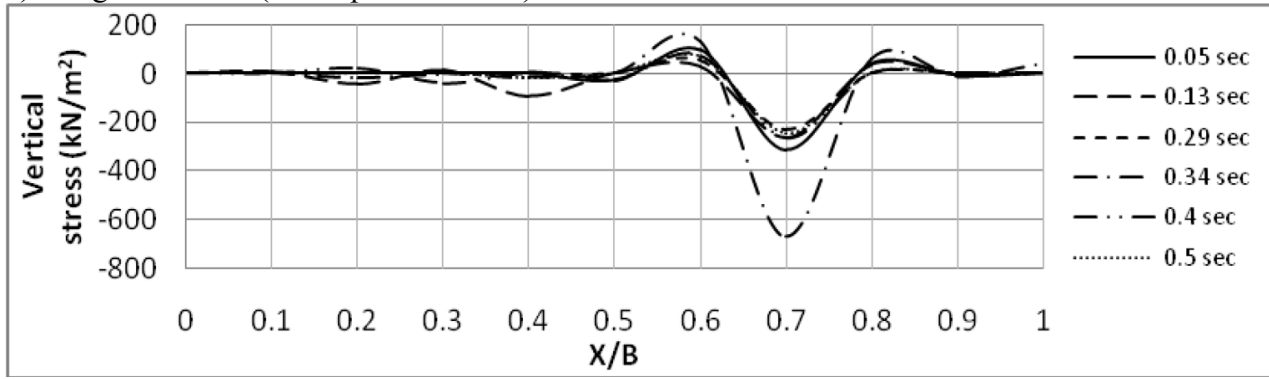

c) along section a-a (for amplitude $75 \mathrm{kN}$ )

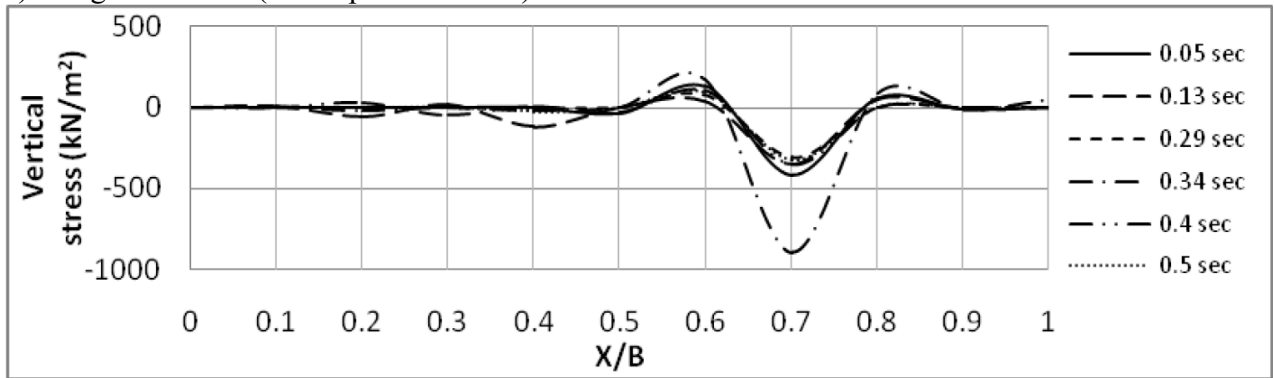

d) along section a-a (for amplitude $100 \mathrm{kN}$ )

Fig. 16: Dynamic response of the foundation to impact load, vertical stress, $t=0.5 \mathrm{~m}, \mathrm{~B}=3 \mathrm{~m}, \mathrm{~L}=3 \mathrm{~m}$, $\mathrm{e} / \mathrm{B}=0.2, \mathrm{D}=0$. 


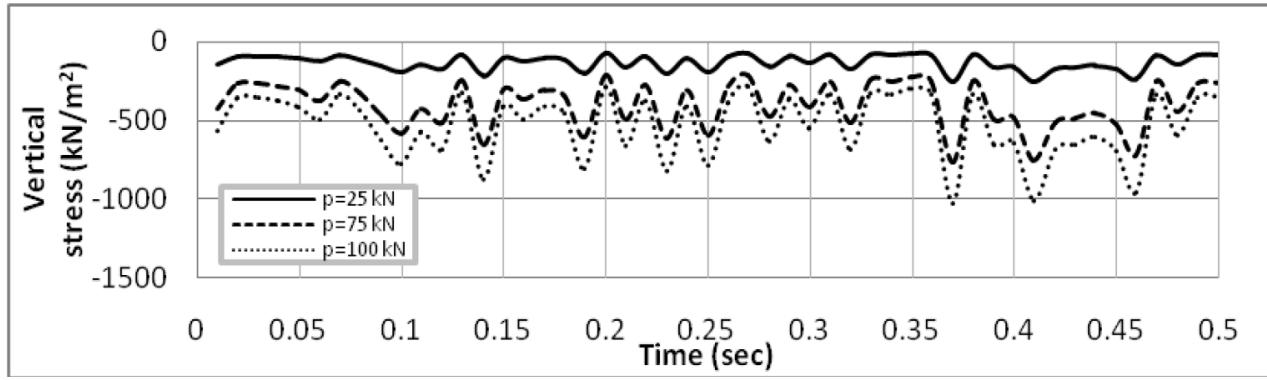

a) at node 81 (center of foundation)

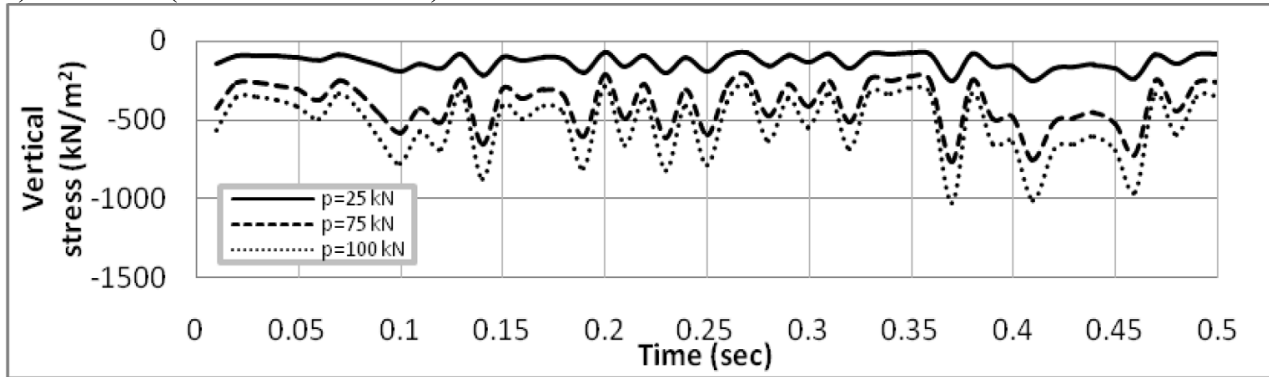

b) along section a-a (for amplitude $25 \mathrm{kN}$ )

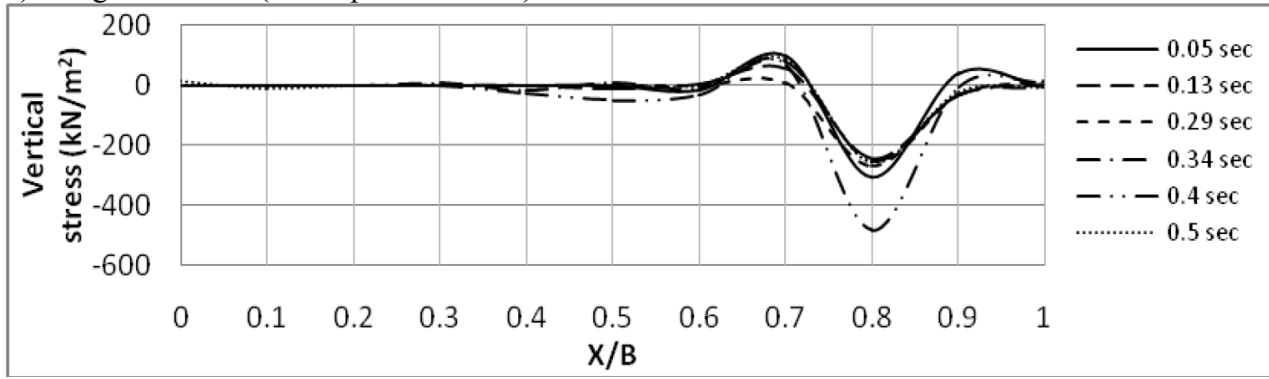

c) along section a-a (for amplitude $75 \mathrm{kN}$ )

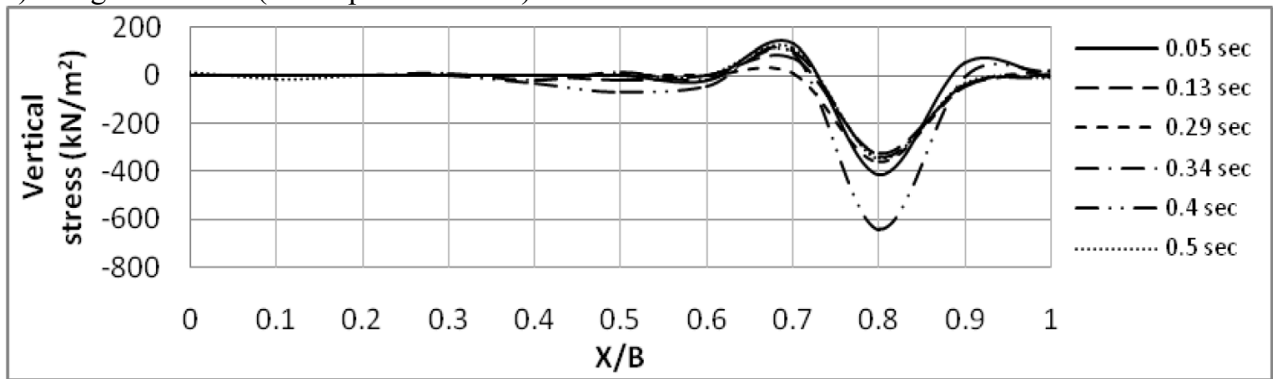

d) along section a-a (for amplitude $100 \mathrm{kN}$ )

Fig. 17: Dynamic response of the foundation to impact load, vertical stress, $t=0.5 \mathrm{~m}, \mathrm{~B}=3 \mathrm{~m}, \mathrm{~L}=3 \mathrm{~m}$, $\mathrm{e} / \mathrm{B}=0.3, \mathrm{D}=0$.

\section{Conclusions}

As a result of the finite element analysis carried out in this study, the following conclusions could be made:

1) As the foundation thickness increases, the time for maximum displacement to take place increases due to the geometrical damping induced by the foundation. When the thickness of foundation increases from $(\mathrm{t}=0.3$ to 0.5 and 0.75 ) $\mathrm{m}$ for amplitude load (po $=25,75$ and 100) $\mathrm{kN}$, the maximum 
vertical displacement at the center of foundation decreases by about 45 and 58 $\%$, and the maximum vertical stress decreases by about 22 and $50 \%$, respectively.

2) The load eccentricity increases the displacement and decreases the stress at the foundation center. This is attributed to non-uniformly distributed stresses on the loaded area, where the loads are concentrated locally within the loaded area. The oscillation of stress for the farther points from the point load increases more than the nearer points. This is because the foundation length on the other side increases making the foundation behaves as a long cantilever beam.

\section{References}

[1] Pavlou, D.G., Bancila, G., Lucaci, R., Belic, F., Dan, D., Pavlou, M. G.,Tirtea, A., Gruin, A. and Baera, C., (2007), "An Exact Solution of the Plate on Elastic Foundation under Impact Loading", 3rd Wseas International Conference on Applied and Theoretical Mechanics, Spain, December 14-16, pp. 79-83.

[2] Winkler, E., (1867), „Die Lehre von der elasticitaet und festigkeit“, Prag Dominicus, Berlin, p.p. 182.

[3] Rao, N. S. V. (2011), "Foundation Design: Theory and Practice", John Wiley \& Sons (Asia), First Edition, Pte Ltd.

[4] Filonenko-Borodich, M. M. (1940), "Some Approximate Theories of the Elastic Foundation (in Russian)", UchenyeZapiski MGU, 46, 3-18.

[5] Hetenyi, M., (1946), "Beams on Elastic Foundations", Ann Arbor, University of Michigan Press.

[6] Pasternak, P. L., (1954), "Fundamental of a New Method of Analysis of an Elastic Foundation by Means of Two Foundation Constants (in Russian)", Gos. Izd.Lit.poStrait i Arkh.,Moscow, USSR.

[7] Kerr, Arnold D (1964). "Elastic and viscoelastic foundation models." Journal of Applied Mechanics 31.3: 491-498.

[8] Teodoru, B. and Musat, V., (2008), "Beam Elements on Linear Variable TwoParameter Elastic Foundation”, University of Gheorghe Asachi, Vol. 3.

[9] Levinton, Z., (1949), "Elastic Foundation Analyzed by the Method of Redundant Reactions", Trans., ASCE, Vol. 114, pp. 40- 52.

[10] Wang, C.M. and How, Y.C., (2001), "Analysis of Rectangular Thick Rafts on an Elastic Half Space”, Computers and Geotechnics, Vol. 28, Issue 3, pp. 161-184.

[11] Al-Azawi, T. K., (1984), "Impact of Reinforced Concrete Slabs", Ph.D. Thesis, University of Sheffield, England.

[12] Abbasi, M.S.A., Baluch, M. H., Azad, A. K. and Abdel-Rahman, H.H., (1992),"Nonlinear Finite Element Modeling of Failure Modes in Reinforced Concrete Slabs", Journal of Computers and Structures, VoI. 42, No. 5, pp. 815-823.

[13] Baidya, E. A., (2004), "Dynamic Response of Footings Resting on a Sand Layer of Finite Thickness", Journal of Geotechnical and Geoenvironmental Engineering, ASCE, Vol. 130, No. 6, pp. 651-655.

[14] Fujikake, K., Li, B. and Soeun, S., (2009), "Impact Response of Reinforced Concrete Beam and its Analytical Evaluation", Journal of Structural Engineering, ASCE, Vol. 135, No. 8, pp. 938-950.

[15] Emrich, F., Herter, J. and Puffer, G., (1982), "Nonlinear Finite Element Analysis of Reinforced Concrete Beams under Impact Load in Comparison with Experimental Results”, Computers and Structures, BAM, Berlin (West), Vol. 4, No. 2, pp. 455-471. 
[16] Miyamoto, A., King, M. W. and Fuji, M., (1991),"Nonlinear Dynamic Analysis of Reinforced Concrete Slabs under Impulsive Loads", ACI Structural Journal, JulyAugust, Vol. 88, No. 4, pp. 411-419.

[17] Tameroglu, S. S., (1996), "Vibrations of Clamped Rectangular Plates on Elastic Foundations Subjected to Uniform Compressive Forces", Journal of Engineering Mechanics, ASCE, Vol. 122, No. 8, pp. 714-718.

[18] Tee, C. H., (2005), "Dynamic Response of Plates and Buried Structures", M.Sc. Thesis, University of West Virginia.

[19] Borgerhoff, M., Stangenberg, F. and Zinn, R., (2011), "Numerical Simulation of Impact Tests of Reinforced Concrete Slabs with Dominating Punching", Transactions, SMiRT 21, New Delhi, India, Vol. 774, pp. 1-8, November 6-11.

[20] Mahmoudpour, S., Attamejad, R. and Behnia, C., (2011), "Dynamic Analysis of Partially Embedded Structures Considering Soil-Structure Interaction in Time Domain", Mathematical Problems in Engineering, Volume 2011, Article ID 534968, 23 pages, doi:10.1 155/2011/534968, Hindawi Publishing Corporation.

[21] Fattah, M. Y., Hamood, M. J., Abbas, S. A., (2013), "Simulation of Behavior of Plate on Elastic Foundation under Impact Load by the Finite Element Method", Engineering and Technology Journal, Special issue, 1st International Conference on Geotechnical and Transportation Engineering, Vol. 31 Part (A), No. 19, pp. 44-58.

[22] ANSYS Manual, Version. 11, (2007): SAS IP, Inc.

[23] Lenczner, D., (1972), "The Elements of Load Bearing Brickwork", 1st Edition, pp. 11-23.

[24] Fattah, M. Y., Hamood, M. J., Abbas, S. A., (2014), "Behavior of Plate on Elastic Foundation under Impact Load", Engineering and Technology Journal, Vol. 32 Part (A), No. 4, pp. 1007-1027.

[25] Teodoru, B., (2009), "Beam on Elastic Foundation the Simplified Continuum Approach", University of Gheorghe Asachi, Vol. 4. 